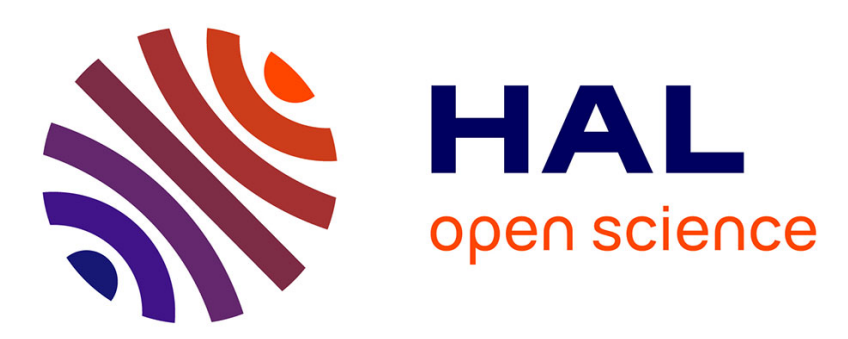

\title{
Geomechanical response of an abandoned chalk mine to multi-annual water table fluctuations
}

\author{
Philippe Gombert, Alain Thoraval, Jean-Marc Watelet
}

\section{To cite this version:}

Philippe Gombert, Alain Thoraval, Jean-Marc Watelet. Geomechanical response of an abandoned chalk mine to multi-annual water table fluctuations. Bulletin of Engineering Geology and the Environment, 2019, pp.3353-3369. 10.1007/s10064-018-1321-7 . ineris-01875958

\section{HAL Id: ineris-01875958}

\section{https://hal-ineris.archives-ouvertes.fr/ineris-01875958}

Submitted on 3 Aug 2021

HAL is a multi-disciplinary open access archive for the deposit and dissemination of scientific research documents, whether they are published or not. The documents may come from teaching and research institutions in France or abroad, or from public or private research centers.
L'archive ouverte pluridisciplinaire HAL, est destinée au dépôt et à la diffusion de documents scientifiques de niveau recherche, publiés ou non, émanant des établissements d'enseignement et de recherche français ou étrangers, des laboratoires publics ou privés. 


\title{
Geomechanical response of an abandoned chalk mine to multiannual water table fluctuations
}

\author{
Philippe Gombert $^{1 *}$, Alain Thoraval ${ }^{2}$, Jean-Marc Watelet ${ }^{1}$ \\ ${ }^{1}$ INERIS, Alata Technology Park, 60550 Verneuil-en-Halatte, France \\ 2 INERIS, Artem Campus, CS 14234, 54042 Nancy cedex, France \\ * philippe.gombert@ineris.fr, ORCID: 0000-0002-0329-3297
}

\begin{abstract}
Summary:
The Paris basin contains 35,000 to 40,000 mines, most of which are abandoned, having mined chalk, a rock very sensitive to water. Although they have been excavated above the groundwater level, some of the mines can be temporarily or permanently flooded, due to (some) exceptional rainfall events. We have thus instrumented the chalk mine of Estreux (Nord department) to measure the impact of the oscillations of the water table on the stability of one of its pillars. It is a mine dug around $20 \mathrm{~m}$ deep by the chambers and pillars method. Now abandoned, it is temporarily flooded when the water table, located a few meters below the mine floor, rises due to heavy precipitation, which occurs on average every 8 years. From 2004 to 2012, a pillar was equipped with a convergence rod and two extensometers. There is a correlation between the vertical and horizontal deformation rates of the pillar and the periodic rise in the water table. Chalk samples were also taken in situ and their geomechanical properties characterized in the laboratory. On this basis, a first 3D mechanical simulation of the behavior of this pillar has been carried out taking into account elasticity, plasticity and creep. The calculated mean values of deformation generally match the measurements and the model succeeds in reproducing the annual fluctuations of these parameters in relation to those of the level of the water table. However, compared to the measurements carried out in situ, the current model exaggerates the vertical deformations compared to the horizontal deformations. However, with this first model we can observe that the variations in the water table induce elastic and reversible deformations of the pillar, given the absence of plastification of the chalk. These deformations are complementary to those due to the creep induced by the weight of the overlying grounds. If we want to model the long-term behavior of the pillar, particularly under the effect of the fluctuations of the water table induced by the climate change in progress, it is necessary to improve this model taking into account the hydromechanical couplings and the flows in unsaturated condition. In conclusion, it is proposed to use these data later in a complete mechanical model, still under development at INERIS.
\end{abstract}

\section{Key words:}

mine, quarry, chalk, piezometry, pillar, convergence, extension, deformation, constraint, simulation, 3D model

\section{Introduction:}

France counts nearly 500,000 natural underground cavities (karst) or artificial cavities (mines, underground shelters ...) (Gombert et al., 2013). Around 6,000 mines were excavated to exploit relatively deep strategic ores (coal, metals ...), while around 300,000 were used to exploit relatively shallow construction materials (limestone, sand, clay, slate ...). Most of these are abandoned and we have often lost track of their exact location. The shallow mines have generally been exploited in the dry, or just above the water table. After their abandonment, the mines can be totally or partially flooded, temporarily or permanently, or subject to changes in their level of flooding, due to exceptional rainfall events. They can also be located within the capillary fringe several to dozens of meters above the water table, and thus be subject to hygrometric fluctuations of their internal atmosphere and / or of the surrounding rock.

The Paris basin counts 35,000 to 40,000 mines, most of which are abandoned, most of which have mined chalk, which is porous and very sensitive to water. Some catastrophic collapses of abandoned underground mines have already occurred, particularly in this area: Château-Landon (7 casualties in 1910), Clamart (21 casualties in 1961), Chanteloup (1 casualty in 1991), Bagnolet (2 casualties in 1993)... (Kreziak \& Watelet, 2016). In some cases, the collapse could be clearly correlated with groundwater inflow (Gombert \& Cherkaoui, 2013) but in other cases, there is still a doubt (Al heib et al., 2015). In this paper, we study the effect of these water table or hygrometric fluctuations on the stability on these old underground works in the case of porous rock as chalk. 
The current climate change is likely to result in changes in evapotranspiration over land, controlled by changes in precipitation and radiative forcing, and these changes would, in turn, impact on the water balance of runoff, soil moisture, water in reservoirs, the groundwater table and the salinisation of shallow aquifers (Bates et al., 2008). In France, increased winter rainfall can be expected, particularly on the Western seaboard and relief, as well as a drop of up to $20 \%$ in winter and autumn rainfall across the country as a whole (MIES, 2000). Since they are replenished principally by rainfall, shallow aquifers are likely to have a higher piezometric level during the winter and a lower one during summer (Didier et al., 2010). Furthermore, this may be amplified and exacerbated in summer by increasingly intense anthropic extraction (in particular for irrigation when there is a lack of surface water). Consequently, a overall increase of the range of water table fluctuations may be expected, with some impact on the flooding level of mines (Gombert \& Cherkaoui, 2013: Gombert et al., 2010).

The Estreux chalk mine has been the subject of INERIS monitoring visits since 2000. During the 2003 visit, a partial flooding was observed and it was decided to instrument a pillar of this mine in order to study its behavior during periods of water intrusion. This instrumentation was carried out in 2004 and since then the few visits made have not revealed the presence of water in the mine although it has probably been flooded several times.

\section{Appearance of the site}

\section{Location and history}

The so-called underground Estreux mine is located $10 \mathrm{~km}$ to the east of Valenciennes, in the Nord department, on a plateau overlooking the right bank of the Scheldt at an altitude of about $60 \mathrm{~m}$. It is a chalk mine of about 10 hectare in area, operated by rooms and pillar and abandoned in the $19^{\text {th }}$ century. The average extraction ratio is $78 \%$ locally reaching $80 \%$, particularly in the instrumented zone. About $20 \mathrm{~m}$ deep, it is temporarily flooded when the water table, about 3-4 m below the mine floor, rises due to heavy rainfall. This rather infrequent flooding, had not been noticed during the first years of the mine visits carried out by INERIS. It was only during the 2003 monitoring visit that it was observed (Figure 1), which led to the instrumentation of one of its pillars in 2004, in the context of studies on the impact of water table fluctuations on the stability of abandoned underground cavities. The follow-up lasted until 2012, when some of the sensors installed broke down, followed by the acquisition unit,.

\section{Here Figure 1}

\section{Geology and hydrogeology}

The mine spreads out into the upper, flint-free part of the glauconous gray chalk of the Upper Turonian, 15 to 25 $\mathrm{m}$ thick. This formation is covered by the white Senonian chalk and then by about ten meters of sandy clays of the Thanetian and by the Quaternary silts and loams (Figure 2).

From a hydrogeological point of view, the studied area is part of to the "chalk layer of Valenciennois" groundwater body. The level of this aquifer has been followed by INERIS from 2007 to 2010 in a piezometer located at the entrance of the mine at an altitude of $57 \mathrm{~m} \mathrm{ASL}$, near the access shaft, and called "mine piezometer". Its depth is $25.4 \mathrm{~m}$ and it shows an average piezometry of $36.2 \mathrm{~m}$ ASL. By comparison, the mine floor, intersected by this piezometer, is here at $37.3 \mathrm{~m}$ ASL, which means that the average water table is $1.1 \mathrm{~m}$ lower than the mine floor.

However, $4 \mathrm{~km}$ northeast of the mine, there is an older piezometer in which the fluctuations of the chalk aquifer have been recorded since 1976. Its altitude (54 $\mathrm{m} \mathrm{ASL),} \mathrm{its} \mathrm{depth}(30.7 \mathrm{~m})$ and its average piezometry (31.1 m ASL) are quite similar to those of the "mine piezometer". Due to its long time series, it can be used as a "reference piezometer" in order to reconstitute the mine piezometry for the last 25 years.

\section{Here Figure 2}

\section{In situ data acquisition}

\section{Geomechanical parameters}

The instrumented pillar is located about $200 \mathrm{~m}$ from the entrance. It has a section of $1.40 \mathrm{~m}^{2}$ and is $1.80 \mathrm{~m}$ high (Figure 3). This pillar is equipped with the following sensors: temperature, interstitial pressure, horizontal extension (Table 1). Nearby, the gallery is also equipped with sensors of temperature, hygrometry and convergence between the roof and the floor. In addition, the water table is recorded in the mine piezometer. 
Here Figure 3

Here Table 1

\section{Piezometry}

The evolution of the chalk water table in the mine aquifer is known through the mine piezometer that intersects the mine between 18.1 and $19.7 \mathrm{~m}$. The water table was monitored by an automatic acquisition probe between 2007 and 2011. Over this period, its mean value is $36.2 \mathrm{~m}$ ASL with a minimum of $35.4 \mathrm{~m}$ ASL and a maximum of $37.4 \mathrm{~m}$ ASL, i.e. an interannual fluctuation of $2.0 \mathrm{~m}$. During the monitoring period, the water table remained on average $1.1 \mathrm{~m}$ below the mine floor, but the mine underwent at least partial flooding between April and June 2009. To this observation, the flooding observed in the spring of 2003 has to be added. It is therefore an irregularly flooded mine whose study lends itself well to the problem posed.

The water table of the chalk aquifer has only been known here since 2007 with unfortunately several episodes of absence of data due to equipment failure. However, the piezometry of this site can be calculated over a longer period and the missing data can be reconstructed, based on the piezometric record available since 1976 in the reference piezometer. To this end, a correlation was made between the average daily piezometric level measured simultaneously for these two piezometers for the period 2007-2011: the coefficient of linear determination reaches 0.980 , which is largely significant, and the correlation function is written:

$\mathrm{NP}_{\text {mine }}=6.66510^{-1} \mathrm{NP}_{\text {piezometer }}+15.53$

(Eq 1)

where $\mathrm{NP}_{\text {mine }}$ is the average daily piezometric level reconstituted at the mine and $\mathrm{NP}_{\text {piezometer }}$, the one measured at the same time at the reference piezometer.

Table 2 shows that the reconstruction of the water table in the mine is consistent with the measurements made during the monitoring period at $\pm 0.1 \mathrm{~m}$. By applying this correlation function to the reference piezometer data for the period 1976-2016, the piezometric level reached at the mine during this period can be reconstructed: on average, it would be 36,2 $\pm 1 \mathrm{~m}$ ASL, value in agreement with the measurements made.

Here Table 2

We have already seen that the mine floor near the access shaft is at $37.3 \mathrm{~m} \mathrm{ASL}$ but the instrumented pillar is located at a hundred meters' distance. Although the mine is generally horizontal, it was estimated, in the absence of levelling, that the level of the pillar could be at $\pm 0.5 \mathrm{~m}$ from this value, i.e., between 36.8 and $37.8 \mathrm{~m}$ ASL.

During the 40.5 years of reconstituted piezometry, these two thresholds were respectively passed 13 and 9 times, i.e., 38 to $14 \%$ of the time. Flooding thus has a return period of 2.6 to 7.4 years with an average water depth of about $1 \mathrm{~m}$ (exceptionally reaching 2 to $3 \mathrm{~m}$ ) for about one year each time (Table 3 ). This piezometric reconstruction is also presented in Figure 4. From this figure, flooding episodes appear to occur when the annual rainfall approximately exceeds the interannual mean of $711 \mathrm{~mm}$ over the period considered.

Here Table 3

Here Figure 4

\section{Laboratory Data Acquisition}

Physical properties of the Estreux chalk

Chalk is a complex porous rock whose mechanical properties naturally exhibit great dispersion due to variability in its mineralogical composition and microstructure (Monjoie et al, 1989; Engstrom 1992; Homand and Shao 2000; Schroeder 2002).

The major component of the chalk is calcite $\left(\mathrm{CaCO}_{3}\right)$, but it may also contain silica, clay, dolomite, glauconite, pyrite, etc. These secondary constituents are likely to be present to a greater or lesser extent in the chalk and affect its geomechanical behavior. 
On a macroscopic scale, the chalk has been extensively studied in mining engineering and in the oil industry. These studies have shown that their mechanical behavior is governed by many factors, such as poor cohesion, sensitivity to strong constraints and strong confinements, plastic pore collapse (Schroeder 1995), viscosity (Dahou et al. 1995; Djebbi 1984), porosity (Monjoie et al., 1989), capillary pressure (Delage et al. 1996), nature of the saturating fluid (Priol et al. 2004) and mineralogical composition (Monjoie et al.1990).

The physical characteristics of the Estreux chalk were determined within the framework of Lafrance's thesis (2016). Essentially composed of micrite $(50 \%)$ and sparite $(24 \%)$, this chalk also contains $23 \%$ glauconite. It has an average porosity of $35 \%$ of which the connected porosity is $31 \%$, as measured by mercury porosimeter. The water content in its natural state is about $19 \%$. Its permeabilities to gas and water are respectively of the order of $10^{-15} \mathrm{~m}^{2}$ and of $310^{-15} \mathrm{~m}^{2}$.

Mechanical behavior of the Estreux chalk in the short and long term

Short-term mechanical tests carried out have been used to characterize this chalk in a dry state and at various degrees of saturation. These tests involve indirect traction and uniaxial compression (Figure 5) and triaxial compression (Figure 6) at a confinement of 0.1 and $3 \mathrm{MPa}$. In dry conditions, its mechanical strength is $0.8 \mathrm{MPa}$ at tensile strength and 13.2 $\mathrm{MPa}$ at uniaxial compression. At full saturation, the tensile strength is divided by two $(0.4 \mathrm{MPa})$ and the compressive strength by more than three $(4 \mathrm{MPa})$, which demonstrates a high sensitivity to water.

Tests of uniaxial and triaxial compression were also carried out on samples of this chalk brought to varying degrees of saturation, ranging from 90 to $98 \%$ following what can be found in situ in the mine (Lafrance et al. 2014). This characterization with controlled humidity has established that the mechanical properties such as the deformability modulus (axial and lateral) and the uniaxial (Figure 5) and triaxial (Figure 6) compression resistance decrease when the relative humidity (or degree of saturation) increases.

\section{Here Figure 5}

Here Figure 6

Creep tests were also carried out, in which each sample is placed in an airtight structure under a controlled humidity atmosphere using saline solutions at a humidity of $85 \%, 90 \%$ and $98 \%$ (Lafrance, 2016). Several stress levels have been imposed $(0.5,1,2$ and $3.5 \mathrm{MPa})$, the last level corresponding approximately to the value of the average vertical constraint in the pillars of the mine, as estimated by the method of the tributary area. After these steps, the test specimens are brought to a hygrometry of $98 \%$ in order to execute a waterborne test, and then rapidly flooded completely with water chemically and thermally balanced with the chalk (keeping the axial constraint at 3.5 MPa and the speed of deformation constant). The results are shown in Figure 7.

It is found that the mineralogy of the Estreux chalk confers it a significant viscoplastic behavior, unlike other less clayey chalks also studied. The creep starts at $85 \%$ saturation, from $1 \mathrm{MPa}$, whereas, at a higher hygrometry deferred deformations appear from 0.5 MPa. The viscoplastic deformations increase nonlinearly with time and the hygrometry for a given deviator, in particular when one moves to a hygrometry of $98 \%$. The final flooding of the sample significantly increases the viscoplastic deformation.

Here Figure 7

\section{Multi-year monitoring of measured parameters in the mine}

\section{Geomechanical parameters}

The monitoring of the geomechanical parameters of the pillar concerns its horizontal deformation (using the double anchor extensometer) and vertical deformation (using the convergencemeter) between 2004 and 2012.

During this period, the extensometer 1 (anchored at $90.34 \mathrm{~mm}$ from the wall) recorded a total extension of 0.13 $\mathrm{mm}$ while the extensometer 2 (anchored at $669.84 \mathrm{~mm}$ from the wall) recorded $0.33 \mathrm{~mm}$. This corresponds to an 
average extension rate of $11 \mu \mathrm{m} . \mathrm{yr}^{-1}$ at around $10 \mathrm{~cm}$ depth and $34 \mu \mathrm{m} . \mathrm{yr}^{-1}$ at around $70 \mathrm{~cm}$. On either side of this average trend, annual fluctuations reaching an amplitude of respectively $40 \mu \mathrm{m}$ and $160 \mu \mathrm{m}$ are observed. The mean horizontal deformation rate of the pillar is thus $1.6710^{-4} \mathrm{yr}^{-1}$ at extensometer 1 and $5.7710^{-5} \mathrm{yr}^{-1}$ at extensometer 2, or 0.167 and $0.058 \mathrm{~mm} . \mathrm{m}^{-1}$ respectively. This evolution in extension in the horizontal plane, comparable to creep, is generally in accordance with what is expected of a pillar subjected to a vertical constraint, but it is found not to be uniform over time (Figure 8). It presents annual oscillations of an amplitude of $210^{-4} \mathrm{yr}^{-1}$ on both sides of the average linear evolution for the extensometer 1 , and about $510^{-4} \mathrm{yr}^{-1}$ for the extensometer 2 : the range of these oscillations is therefore greater than the average annual deformation while remaining of the same order of magnitude. In addition, these oscillations are well synchronized with those of the piezometric level, the horizontal deformation tending to increase when the piezometric level is high and to decrease when it is low.

\section{Here Figure 8}

As to the vertical deformation of the pillar, the $2 \mathrm{~m}$ high convergencemeter (or convergence rod) placed in the gallery showed a total contraction of $0.88 \mathrm{~mm}$ over the period considered, i.e., a contraction rate of about 106 $\mu \mathrm{m} . \mathrm{yr}^{-1}$. This corresponds to an average deformation rate of $5.1910^{-5} \mathrm{yr}^{-1}$ (i.e., $0.052 \mathrm{~mm} . \mathrm{m}^{-1}$ ). This vertical deformation appears to be linear over time (Figure 9a) and very little affected by fluctuations in the water table. However, by analyzing it in detail, one also notes oscillations with respect to its average evolution (Figure 9b). The average range of these oscillations generally remains less than $40 \mu \mathrm{m}$ : in terms of deformation, this corresponds to oscillations of $210^{-5} \mathrm{yr}^{-1}$, that is, of the order of magnitude of half the mean annual deformation. Here, we reach the limits of the sensitivity threshold of the device $( \pm 20 \mu \mathrm{m})$ but it can be noted that these oscillations appear to be synchronous with the piezometric fluctuations and that, as before, the verticaldeformation tends to increase when the piezometric level is high and to decrease when it is low.

\section{Here Figure 9}

Thus, it seems that the periods of high water table favored the deformation of the pillar, more distinctly in the horizontal than in the vertical plane. The geomechanical parameters of the pillar thus seem to be sensitive to the differences in water content of the rock induced by the fluctuation of the water table within the capillary fringe. Observations carried out in situ show that the deformation of the pillar tends to increase at the same time as the piezometric level and therefore the degree of water saturation of the chalk. These observations are in agreement with the results of the laboratory tests which show a high sensitivity of this chalk to its water content. Wiid (1967) and Watelet (1996) had already shown similar behavior in the laboratory by performing uniaxial compression tests on several porous rocks at different degrees of saturation: according to their experiments, the absorption of water results in a decrease in the compressive strength of the rock which, for chalk, is of the order of $10 \%$ when the water saturation increases from $80 \%$ to $100 \%$. These authors assumed that water saturation favored the creep of this porous rock, which chalk is, and thus led to an increase in its deformation whereas, conversely, its desaturation would lead rather to a phenomenon of retraction, generally accompanied by tension cracks. We have therefore attempted to reproduce this behavior by means of a numerical simulation, in particular to predict the long-term behavior of such a pillar and to anticipate a possible risk of rupture in the event of a significant and lasting rise in the water table, linked for example to climate change in progress (Didier et al., 2010; Gombert et al, 2010, 2013).

\section{D mechanical simulations of the long-term behavior of the pillar}

\section{Design of the model}

The goal of the modeling is to study the impact of the fluctuation of the water table on the evolution of the deformation of the pillar. For this, a 3D model has been developed to simulate the elasto-visco-plastic behavior of a chalk pillar, taking into account its short and long-term behavior. The chalk behavior has been described by combining a creep law associated with an elasto-plastic law with a failure criterion.

The model used to simulate the chalk creep is the Norton model (Norton, 1929). The uniaxial formulation of this model is:

where :

$$
\dot{\varepsilon}=a \exp \left(-\frac{Q}{R T}\right)\left(\frac{\sigma}{\sigma_{0}}\right)^{n}=A\left(\frac{\sigma}{\sigma_{0}}\right)^{n}
$$

$\dot{\varepsilon}$ is the rate of axial deformation of a cylindrical sample subjected to an initial stress $\mathrm{p}$ and a confinement stress q, knowing that $\sigma=\mathrm{p}-\mathrm{q}$. If $\sigma$ is expressed in $\mathrm{MPa}$, we consider that $\sigma_{0}$ is equal to $1 \mathrm{MPa}$;

- $\quad \mathrm{T}$ is the temperature of the sample $[\mathrm{K}]$; 
- $\quad \mathrm{a}, \mathrm{A}[1 / \mathrm{s}], \mathrm{Q} / \mathrm{R}[\mathrm{K}]$ and $\mathrm{n}[-]$ are the parameters of the law. In the simulation, the temperature is assumed to remain constant.

Plasticity appears primarily in the instantaneous response, but also in the long term as a consequence of strength reduction with time. In general, a plastic model is characterized by its yield function (or criterion) $F(\sigma)$, a hardening/softening function and a flow rule $G(\sigma)$. The yield function defines the stress combination for which plastic flow takes place. The flow rule specifies the direction of the plastic strain increment vector as normal to the potential surface.

The Mohr-Coulomb shear criterion, characterized by the cohesion $\mathrm{C}$ and friction angle $\varphi$, is represented by an irregular hexagonal pyramid. The Drucker-Prager parameters $\mathrm{q} \varphi$ and $\mathrm{k} \varphi$ can be adjusted so that the Drucker-Prager cone will either pass through the outer or the inner edges of the Mohr-Coulomb pyramid. In the present case, we assumed a inner adjustment allowing to express the Drucker-Prager yield function as follows (Detournay, 1988):

$$
F(\sigma)=F(p, q)=q+q_{\varphi} p-k_{\varphi}=q+\frac{6 \sin \varphi}{3+\sin \varphi} p-\frac{6 C \cos \varphi}{3+\sin \varphi}
$$

where $\mathrm{q}$ is the deviatoric stress and $\mathrm{p}$ is the mean stress.

Finally, for the sake of simplicity, we consider a standard (where the potential and yield functions coincide: $G=$ F) and an elastic perfectly plastic behavior, considering that the peak and residual strength are the same, which can be considered as a model limitation considering the real post-peak chalk behavior (as we can see in figures 5 and 6).

The preliminary approach proposed in this paper partially decouples the elastoplastic model (with a DruckerPrager yield surface) and the creep model (Norton law). Assuming that the total strain are the sum of reversible strains (elastic part), irreversible instantaneous strains (due to plasticity) and irreversible time-dependent strains (due to creep), we proceed as follow. At each time step:

- the irreversible time-dependent strains are calculated (using the creep model) from the state of stress calculated previously (especially the deviatoric stress here),

- the sum of the elastic strain and the irreversible instantaneous strains are estimated subtracting from the total strain the irreversible time-dependent strains computed previously,

- $\quad$ the irreversible instantaneous strains and the admissible stresses are estimated (as usual) from the elastoplastic model considering the Drucker-Prager yield surface and assuming the plastic flow rule and the consistency condition.

This approach is not perfect since it neglects some coupling terms between plasticity and creep. However, we believe that it allows a rough appreciation of the combined impact of creep and plasticity of chalk. We hope to have the opportunity to improve our model soon from the recent work of Ineris done by Lafrance (2016) and Souley $(2016,2017)$. Those 2 last publications describe the writing and numerical implementation of a hydroelasto-visco-plastic model, and its application to chalk behavior simulation.

The model takes into account vertical symmetry planes passing through the center of the pillar and contiguous chambers (Figure 10), which amounts to assuming a perfect regularity of the mining. The geometry of the modeled pillar corresponds to that of the instrumented pillar: $3 \mathrm{~m}$ high for $2 \times 2 \mathrm{~m}$ sides. We have also shown in Figure 13 the convergence and expansion measures that have been carried out.

The initial states of stress are a vertical stress $\sigma_{\mathrm{v}}$ equal to the weight of the overburden and a isotropic horizontal stresses equal to $\sigma_{h}=v /(1-v) \times \sigma_{v}$. The following boundary conditions have been applied: no vertical displacement at the base of the model, no normal displacement in the vertical boundaries assumed to be planes of symmetry, zero normal stress at the surface plane and at the chamber walls.

\section{Here Figure 10}

The fluctuations in the piezometric level entered in the model correspond to the actual data measured in situ between 2004 and 2012: the groundwater level varied between about 19.6 and $23.6 \mathrm{~m}$ depth, i.e. between $37.3 \mathrm{~m}$ ASL and $35.3 \mathrm{~m}$ ASL (see Figure 4). The simulation takes into account the effects of water in an indirect way, i.e., through a variation of the geotechnical characteristics of the chalk according to the position of the point considered:

- $\quad$ Below the piezometric level, its properties are those of a saturated chalk;

- Above the piezometric level, the chalk is no longer completely saturated, its properties are assumed to evolve, as a function of the distance to the water table, from those of a saturated chalk to those of a desaturated chalk. 
Other hydromechanical couplings (notably the effect of interstitial pressure on effective stress) as well as the $\mathrm{kr} /$ $P c$ relationships which connect the relative $k r$ permeabilities and the $P c$ capillary pressure to the variations in water saturation are not taken into account here.

The geomechanical characteristics chosen for the simulation are summarized in Table 4 for saturated or dry chalk. Considering the small in situ chalk fracturation (as we can see on photos), no size effect has been taken into account. However, a small reduction of the cohesion $\mathrm{C}$ has been made to indirectly take into account the postrupture behavior. Indeed the model considers a perfectly plastic behavior (with $C_{\text {peak }}=C_{\text {res }}$ ). The two following settings have been considered : $\mathrm{C}_{1}=0.75^{*} \mathrm{C}_{\text {lab }}$ and $\mathrm{C}_{2}=0.6^{*} \mathrm{C}_{\text {lab }}$. Taking $\mathrm{C}=\mathrm{C}_{1}$ or $\mathrm{C}_{2}$ in this situation can be a good way to approach a post peak behavior with residual cohesion, a little smaller than the peak cohesion (considering $\mathrm{C}_{\text {peak }}=\mathrm{C}_{\text {lab }}$ and $\mathrm{C}_{\mathrm{res}}=\mathrm{C}_{1}$ or $\mathrm{C}_{2}$ ).

The creep parameters $\mathrm{n}$ and A have been chosen in order to reproduce the long term deformation of the pillar.

\section{Here Table 4}

\section{The capillary fringe}

We have seen above that for at least $62 \%$ of the time, the water table is between 2 and $3 \mathrm{~m}$ under the mine floor. The question arises as to whether the pillars and the walls of the mine are always in the capillary fringe above the water table, that is to say in a zone of high water content which varies over time. This can be roughly verified by calculating the theoretical height of this fringe on the basis of Jurin's law, which is:

where:

$$
h=\frac{2 \gamma \cos (\theta)}{r \rho g}
$$

- $\mathrm{h}$ is the height at which the water rises by capillarity $(\mathrm{m})$;

$-\gamma$ is the surface tension of the water which is about $7.410^{-2} \mathrm{~N}^{-1} \mathrm{~m}^{-1}$ at $12^{\circ} \mathrm{C}$ (average temperature within the cavity);

- $\rho$ is the density of water, i. e., $10^{3} \mathrm{~kg} \cdot \mathrm{m}^{-3}$;

- $g$ is the acceleration of gravity, i. e., $9.81 \mathrm{~m} . \mathrm{s}^{-2}$;

- $\theta$ is the water-rock contact angle; its exact value for the chalk being unknown, an average value of $55^{\circ}$ was chosen which is intermediate between the values of $44^{\circ}$ and $66^{\circ}$ found in the literature for various materials; - $\mathrm{r}$ is the radius of the capillary tube, assimilated to the average equivalent radius of a pore of the matrix chalk; we have taken here the value of the access radius $(0.7 \mu \mathrm{m})$ which was measured by Nguyen (2009) for this chalk.

On the basis of these data, the height of the capillary fringe above the water level would be $12 \pm 3 \mathrm{~m}$. This implies that the mine is permanently within the capillary fringe of the groundwater, even during a pronounced low-water period: thus, when the water table is at its minimum observed level (that is, $22 \mathrm{~m}$ deep), the capillary fringe would affect the entire chalk formation hosting the mine, up to $4 \mathrm{~m}$ above its roof.

In other words, we have assumed that in the fringe zone (see next section), the mechanical properties (E, v, C, $\varphi$ and A) change from those of a dry chalk to those of a saturated chalk, considering a variation of the water table with time (according to the measurements made). At the ground water level and below, the chalk is assumed to be fully saturated, and $10 \mathrm{~m}$ above the water table (i.e. at the top of the capillarity fringe), it is assumed to be dry. In between, the mechanical properties are assumed to change linearly with the distance from the water table.

\section{Results - total deformation}

For each of the two cohesion settings $\left(\mathrm{C}_{1}\right.$ and $\left.\mathrm{C}_{2}\right)$, the displacement and deformation variations induced by the water table fluctuation were calculated for the period 2004-2012 (Figure 11). The simulations show that the behavior of the chalk remains elastic considering $C_{1}$ as the cohesion value, while a plastification appears in the centre of the pillar considering $\mathrm{C}_{1}$.

In this case, the model predicts that effective plastic strain (total plastic strain induced by deviatoric stresses) appears during the strong rise of the water table during the spring of 2009 when it reached a piezometry of $37.4 \mathrm{~m}$ 
ASL, i.e. above the mine floor (Figure 12). As we can see in figure 11, the effective plastic strain increased up to $10^{-3} \mathrm{~m} \cdot \mathrm{m}^{-1}$ in a few months and remained constant.

\section{Here Figure 11}

We have also computed the evolution of the effective creep strain (total creep strain induced by deviatoric stresses). As we can see in figure 12, the plastic creep strain almost linearly increases with time up to $7.910^{-4} \mathrm{~m} . \mathrm{m}^{-1}$. There is not so much connection with the water table variation although the parameter A is assumed to change with chalk saturation, depending on the distance of the pillar to the water table.

We have checked whether the effective creep strain evolution depends on the cohesion value, considering little changes induced in the deviatoric stress values. It appears that the maximum value (reached after 8 years) of the effective creep strain is a little bit lower $\left(7.110^{-4} \mathrm{~m} \cdot \mathrm{m}^{-1}\right)$ with a chalk cohesion equal to $\mathrm{C}_{1}$.

\section{Here Figure 12}

\section{Results - horizontal deformation}

For each setting of parameter $\mathrm{C}$, the evolution over time of the horizontal deformation of the pillar and of the vertical convergence of the gallery was calculated by comparing them with the measurements carried out in situ (Figure 13). It is recalled that the average in situ extension velocity varies from $11 \mu \mathrm{m} . \mathrm{yr}^{-1}$ (at $10 \mathrm{~cm}$ depth) to 34 $\mu \mathrm{m} . \mathrm{yr}^{-1}$ (at $70 \mathrm{~cm}$ depth), with annual oscillations respectively in the range of 40 to $160 \mu \mathrm{m}$.

The model based on the $\mathrm{C}_{1}$ cohesion value provides an average horizontal extension of 4 to $28 \mu \mathrm{m}$. $\mathrm{yr}^{-1}$ depending on the depth under consideration, with annual oscillations ranging from 2 to $10 \mu \mathrm{m}$. It can be seen that while the calculated mean extension rates remain in the order of magnitude of the measured values in situ, the range of annual oscillations is not well reproduced: the modeled values are 16 to 20 times lower than those from the instrumented pillar.

The reduction of the cohesion $\left(\mathrm{C}_{2}\right.$ setting) results in a sudden and irreversible increase in the extension rate at $\mathrm{t}=$ 5 years, corresponding to a strong rise in the water table, which induces the plastification of the pillar (see dotted curves in Figure 13).

It is thus the $\mathrm{C}_{1}$ setting which provides the results which are closest to reality in terms of simulation of horizontal deformations.

\section{Here Figure 13}

On the basis of the previous model, calibrated with the $\mathrm{C}_{1}$ setting, the theoretical horizontal deformations of the mine pillar were simulated over the period covered by the piezometric surveys, i.e., from 1976 to 2012 . The objective of this calculation is to see if the larger water table fluctuations observed prior to the calibration period may induce plastification of the pillar and thus additional irreversible displacements. In the simulated 35.6 years, we obtain:

- $\quad$ an average creep extension rate from $0.003 \mathrm{~mm} \cdot \mathrm{yr}^{-1}$ (at $10 \mathrm{~cm}$ depth) to $0.028 \mathrm{~mm} . \mathrm{yr}^{-1}$ (at $70 \mathrm{~cm} \mathrm{depth)}$ (Figure 14a);

- $\quad$ about 32 to 33 cycles of deformation of an average range of $0.001 \mathrm{~mm}$ (at $10 \mathrm{~cm}$ depth) to $0.009 \mathrm{~mm}$ (at $70 \mathrm{~cm}$ depth), related to the impact of variations in the water table (Figure 14b).

We observe that the oscillation cycles of the extension occur almost every year, in connection with the fluctuations of the water table. They lead to displacements complementary to those linked to the creep, but, given the absence of plastification of the chalk, these displacements are linked to an elastic and reversible deformation of the layers which disappears when the water table returns to its initial position. 


\section{Results - vertical deformation}

It is noted that the in situ convergence measurements of the gallery show a very regular evolution at a rate of about $106 \mu \mathrm{m} . \mathrm{yr}^{-1}$ with low oscillations in relation to the water table, of less than $40 \mu \mathrm{m}$.

The rate of convergence calculated according to the $C_{1}$ setting oscillates for 4 years around the mean value measured in situ (Figure 15). From $\mathrm{t}=5$ years onwards, when the period of high ground water level occurs, the calculated value remains at a high value of around $230 \mu \mathrm{m} . \mathrm{yr}^{-1}$, i.e., twice the measured value. Contrary to what we saw previously with the horizontal deformation, we obtain here larger annual oscillations: they range in the order of $200 \mu \mathrm{m}$ in the model, i.e., approximately 5 times more than the measured values.

Using the $\mathrm{C}_{2}$ setting, which reduces the cohesion value, the simulated result is almost the same for the first 4 years, then it shows an abrupt, large (about $1 \mathrm{~mm}$ ) and irreversible increase in convergence at $\mathrm{t}=5$ years. After this period, the convergence rate resumes the same value as previously simulated (about $230 \mu \mathrm{m}_{\text {. }} \mathrm{yr}^{-1}$ ) with oscillations of the same order of magnitude. However, the average convergence thus calculated over 8 years would be of the order of $290 \mu \mathrm{m} . \mathrm{yr}^{-1}$, i.e., almost three times the measured value.

As with the previous horizontal deformations, it is therefore $\mathrm{C}_{1}$ the setting that provides the results closest to reality in the simulation of vertical deformation.

\section{Here Figure 15}

On the basis of the model, calibrated with the $\mathrm{C}_{1}$ setting, the theoretical vertical deformations of the pillar were also simulated from 1976 to 2012 (period covered by the piezometric surveys). An average convergence rate of $0.21 \mathrm{~mm} . \mathrm{yr}^{-1}$ was obtained (Figure 16a), with about 35 annual cycles with an average range of $0.12 \mathrm{~mm}$ (Figure 16b). Again, these cycles of oscillating convergence occur almost every year, in relation to fluctuations in the water table, but only induce elastic and reversible deformation of the chalk.

\section{Here Figure 16}

\section{Discussion of the results}

For the 4 years for which in situ measurements are available, the values obtained by the modeling are compared in Table 5. The table shows that:

- the calculated convergence is about twice its measured value in situ, while the inverse phenomenon is observed for the extension: depending on the depth under consideration, the calculated extension is up to 3 times lower than the measured value;

- the range of the annual oscillations of the vertical deformation is 5 times higher in the model than in the instrumented pillar, but paradoxically 2 to 3 times lower for horizontal deformations.

\section{Here Table 5}

The 3D modeling thus makes it possible to reproduce in a general way the behavior of the pillar under the double effect of the stesses induced by the weight of the overlying grounds and the fluctuations of water table. The latter are supposed to modify the water content of the rock, which influences its mechanical strength. Of the two cohesion settings used, the $C_{1}$ setting provides mean values of vertical and horizontal deformation which are globally of the same order of magnitude as those measured in situ. On the other hand, as soon as the water level rises (even without causing the flooding of the mine), the $\mathrm{C}_{2}$ setting systematically induces the appearance of a plastification which results in a sudden irreversible high amplitude deformation which has not been observed in situ.

Over the 2007-2011 period used to calibrate the model, the water table varied from 35.4 to $37.4 \mathrm{~m}$ ASL, a fluctuation of $2.0 \mathrm{~m}$. During the period 1976-2016, the reconstituted piezometry has most likely varied from 34.4 to $39.8 \mathrm{~m}$ ASL, a fluctuation which would have reached $5.4 \mathrm{~m}$. The modeling of the medium-term behavior of the pillar shows that its deformation undergoes cycles modeled on those of the piezometry and that this induces a deformation complementary to the creep but which does not generate irreversible deformations.

In the longer term, with the current climate change, this fluctuation could be further enhanced by the combined effect of the increase in the amount of winter precipitation and the duration of the summer low levels (Didier et 
al., 2010; Gombert \& Cherkaoui, 2013; Gombert et al., 2010). It is therefore interesting to comprehend the geomechanical behavior of the pillar in response to these new stresses of greater frequency and magnitude. However, in comparison with the measurements made, the current model assigns too much importance to vertical deformation (convergence) with respect to the horizontal deformation (extension) and it does not correctly reproduce the range of their annual oscillations. This model must therefore be improved before it can be applied to a longer time series of piezometric data: we propose to do this by using a complete mechanical model, currently under development, which will take into account the hydromechanical couplings as well as the two phase flow under unsaturated conditions.

\section{Conclusion}

Some catastrophic collapses of abandoned underground mines have already occurred, particularly in the chalk of the Paris basin. In some cases, these events have been clearly correlated with groundwater inflow. This paper studies the effect of water table or hygrometric fluctuations on the stability of old underground works in the case of porous and water-sensitive rock as chalk.

In this context, a chalk mine near Estreux in the north of the Paris basin has been selected by Ineris. Although excavated above the water table, around $20 \mathrm{~m}$ deep, it undergoes partial flooding episodes on average every 8 years, with a duration of about one year. The maximum water level is likely to fully flood the mine. One pillar of this mine has been instrumented and monitored from 2004 to 2012, in order to study its reaction to the variations of the water table, and in particular to periods of flooding.

In response to the natural stress imposed by the weight of the overlying grounds, the instrumented pillar undergoes a vertical contraction which results in a horizontal deformation. The average deformation rate measured is $106 \mu \mathrm{m}$.year-1 in the vertical plane and 11 to $34 \mu \mathrm{m}$.an-1 in the horizontal plane, depending on the depth of the sensors. This average value is disturbed by annual oscillations which are linked to those of the ground water level: it can thus be seen that the horizontal and vertical deformation rates increase during periods of rising ground water levels and that they drop during periods of low water levels. The annual range of these oscillations is very significant: taking into account the average deformation rates, it represents the equivalent of 5 months of convergence and 4 years of extension. It was considered that this was due to an acceleration of the creep rate induced by the increase in water content of the chalk: this increase occurs not only during flooding but also during phases of a significant rise in the piezometric level since the mine lies within the capillary fringe of the phreatic water table.

This hypothesis is confirmed by laboratory tests realized on this chalk. It is observed that for a given deviator, its viscoplastic deformations increase nonlinearly with time and with the hygrometry, in particular when a saturation of $98 \%$ is exceeded. The final flooding of the sample then significantly increases the range of these viscoplastic deformations.

A 3D modeling has been performed to reproduce this behavior with two distinct chalk cohesion values $(75 \%$ and $60 \%$ ), derived from laboratory tests. While the lower value induces the appearance of a plastification not observed in situ, the higher one makes it possible to largely reproduce the behavior of the pillar under the effect of the modification of the water content of the rock. Such a modification acts on its mechanical resistance, in relation to the fluctuations of the water table. Although the average calculated values of deformation are of the same order of magnitude as those measured in situ, it is noted that the vertical deformation is overestimated and the horizontal deformation underestimated.

Finally, the 3D modeling currently performed reproduces the observed phenomenon quite correctly but gives too much weight to the convergence with respect to the extension, and it does not accurately reproduce the range of their annual oscillations, as measured at the instrumented pillar. This model needs to be improved before it can be applied to a longer time series of piezometric data, notably to simulate the impact of climate change on the longterm stability of the mine. It is therefore planned to use these data in a complete mechanical model, currently under development at Ineris.

Nevertheless, this first simulation of the long-term behavior of this pillar has shown that it must undergo cycles of vertical and horizontal deformation molded on those of the piezometry. These cycles induce deformations complementary to the creep, while remaining in the elastic and reversible range. The question of a potential unstability of such abandoned mines depends on the long term behavior of the pillars at (i.e. after several cycles) 
and/or during extreme flood events as seen in this mine in 2001. The climate change scenarios show that extreme rainfall events, likely to produce such flood events, could be more frequent in the second part of the 21 th century.

\section{Bibliography}

Al Heib M, Duval C, Theoleyre F, Watelet JM, Gombert P (2015) Analysis of the historical collapse of an abandoned underground chalk mine in 1961 in Clamart (Paris, France). Bull Eng Geol Environ (2015) 74:10011018, DOI 10.1007/s10064-014-0677-6.

Bates BC, Kundzewicz ZW, Wu S, Palutikof JP, Eds. (2008) Climate Change and Water. Technical Paper of the Intergovernmental Panel on Climate Change, IPCC Secretariat, Geneva, 210 p.

Dahou A, Shao J, Bederiat M (1995) Experimental and Numerical Investigations on Transient Creep of Porous Chalk. Mechanics of Materials 21 (2), 147-58.

Didier C, Al Heib M, Gombert P, Charmoille A (2010) Impact of climate change on the stability of underground cavities: State of knowledge. Report INERIS DRS-10-103862-00411A.

Delage P, Cui YJ, Schroeder C (1996) Subsidence and Capillary Effects in Chalks. In Proceedings of the ISRM International Symposium on Prediction and Performance in Rock Mechanics and Rock Engineering (EUROCK 96), 1291-99. Turin, Italy.

Detournay E, Cheng AHD (1988) Poroelastic Response of a Borehole in a Non-Hydrostatic Stress Field, Int. J. Rock Mech. Min. Sci. \& Geomech. Abstr., 25(3), 171-182.

Djebbi M (1984) Dissolution-crystallization phenomenon: bibliographic study and application to chalk creep. PhD Thesis, University of Lille 1 - Science and Technology.

Engstrøm F (1992) Rock mechanical properties of Danish North Sea chalk. Proceedings of 4th North Sea Chalk Sym, Deauville.

Gombert P, Auvray C, Al Heib M (2013) In-situ and laboratory tests to evaluate the impact of water table fluctuations on stability of underground chalk mines. Procedia Earth and Planetary Science 7 (2013) 304-308.

Gombert P, Cherkaoui A (2013) Role of water in the stability of abandoned and partially or temporarily flooded underground quarries and expected impact of climate change. Tunnels and Underground Areas, 240, 468-482.

Gombert P, Auvray C, Al Heib M (2013) In-situ and laboratory tests to evaluate the impact of water table fluctuations on stability of underground chalk mines. Procedia Earth and Planetary Science 7 (2013), 304-308.

Gombert P, Damart V (2012) Stability of abandoned underground quarries in relation to fluctuations in flood level. National Geotechnical and Geological Engineering Conference JNGG2012, July 4-6, 2012, Bordeaux, France.

Gombert P, Cherkaoui A, Al Heib M, Didier C, Bentivegna G (2010) Role of piezometric fluctuations on the stability of underground cavities in the context of climate change. 23rd Meeting of Earth Sciences, Bordeaux, 25 26 Oct. 2010

Homand S, Shao JF (2000) Mechanical Behaviour of a Porous Chalk and Effect of Saturating Fluid. Mechanics of Cohesive-Frictional Materials 5 (7), 583-606.

Kreziak C, Watelet JM (2016). Analysis and questionning on 1910 collapse of Lorroy chalk underground quarry. Actes de la conférence, JNGG 2016, 6-8 juillet 2016, Nancy, France, 8 p.

Lafrance N (2016) Study of the effects of water on the phenomena of rupture and deformation affecting underground chalk quarries. $\mathrm{PhD}$ thesis, University of Lorraine, Nancy, France.

Lafrance (2016) Study of the effects of water on the phenomena of rupture and deformation affecting underground chalk quarries. PhD thesis, University of Lorraine, Nancy, France.

Lafrance N, Souley M, Auvray C, Favreau O, Labiouse V (2014) Aging of chalk rocks in an underground quarry. Rock Engineering and Rock Mechanics: Structures in and on Rock Masses: proceedings of the international symposium EUROCK 2014. Leiden: CRC Press, 2014, 445-450.

MIES, 2000. Impacts potentiels du changement climatique en France au XXI ${ }^{\mathrm{e}}$ siècle (The potential impacts of climate change in France in the $21^{\text {st }}$ century). Inter-ministry report on the greenhouse effect.

Monjoie A, Schroeder C (1989) Mechanical characteristics of upper Cretaceous chalks. In CFMR - Chalk Conference. Lille, France.

Monjoie A, Schroeder C, Prignon P, Yernaux C (1990) Establishment of Constitutive Laws of Chalk and Long Term Tests. Third North Sea Chalk Symposium, Copenhagen, Denmark.

Nguyen HD (2009) Influence of water-rock interactions on the long-term behavior of underground cavities in chalk. Doctoral thesis, National School of Bridges and Highways. 
Norton FH (1929) Creep of steel at high temperatures. McGraw-Hill Book Co., New York.

Priol G, De Gennaro V, Delage P, Cui YJ (2004) On the suction and the time dependent behaviour of reservoir chalks of North sea oilfields. Proc. $2^{\text {nd }}$ Int. Workshop on Unsaturated Soils, Capri (Italy), 43-54.

Schroeder C (1995) The "Pore-Collapse": particular aspect of the skeletal fluid interaction in chalks? In International Colloquium "Chalks and Shales." Brussels, Belgium.

Schroeder C (2002) From coccolith to petroleum reservoir: phenomenological approach to the mechanical behavior of chalk for modeling at different scales. Thesis of applied sciences, University of Liège, Belgium.

Souley M, Armand G, Kazmierczak JB (2017) Hydro-elasto-viscoplastic modeling of a drift at the Meuse/HauteMarne underground research laboratoratory (URL. Computers and Geotechnics, 85 (2017), 306-320.

Souley M, Lafrance N, Auvray C, Labiouse V, Belem T (2016) An elastoplastic and viscoplastic model for highly porous geomaterials : application to two chalks of the Parisian Bassin. Rock Mechanics and Rock Engineering : From the Past to the Future : Proc. of the Int. Symp. EUROCK 2016. NC : CRC Press, 2016, 481-486.

Watelet JM (1996) Method of analysis and diagnosis of the conditions of stability of underground quarries. Report of a CNAM engineer in geological engineering of construction, Paris, France.

Wiid BL (1967) The influence of moisture upon the strength behaviour of rock, Ph.D. Thesis. University of Witwatersrand, $184 \mathrm{p}$. 

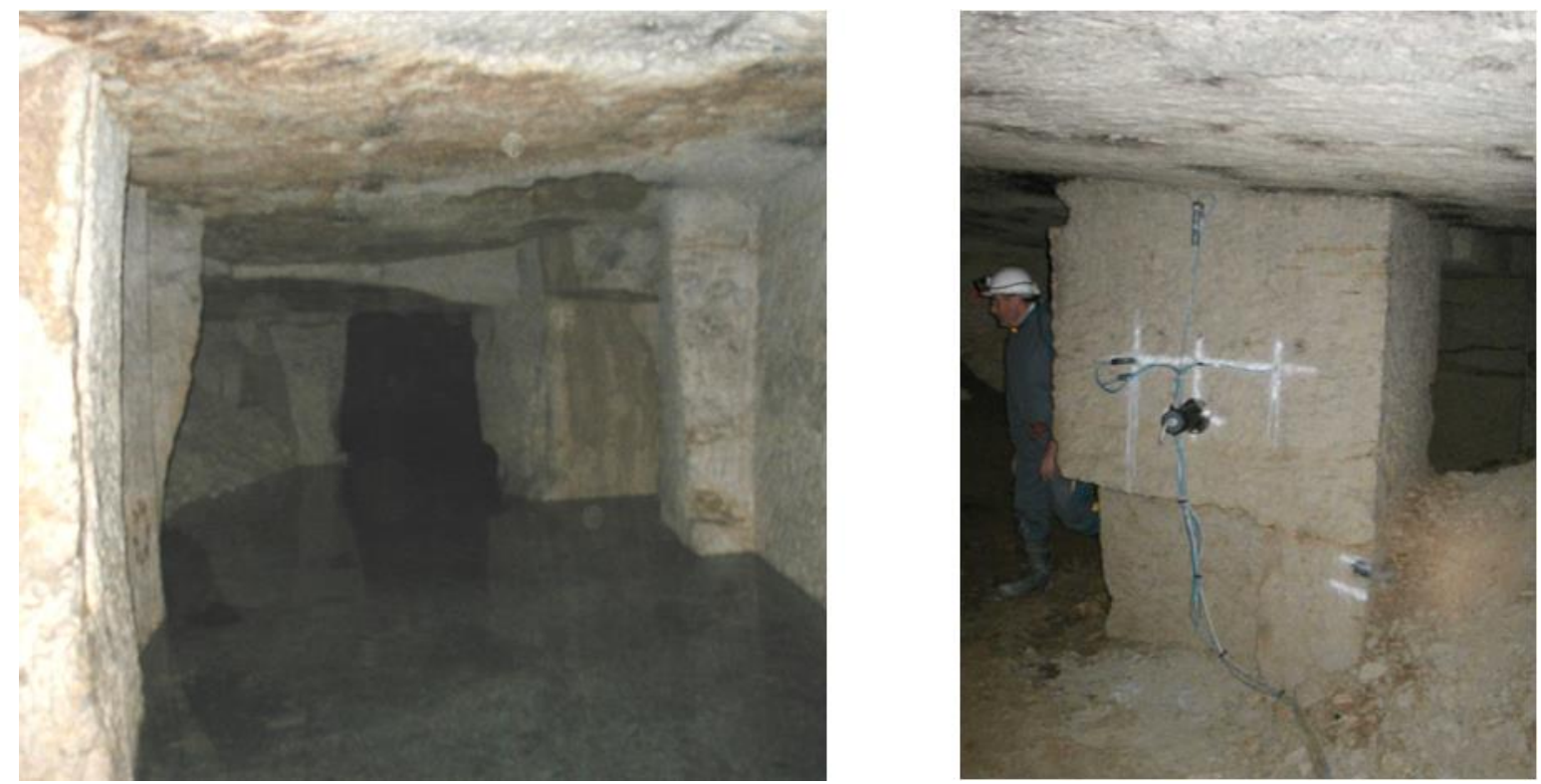

Figure 1. Flooding observed in 2003 (at left) and instrumented pillar in 2004 (at right) 


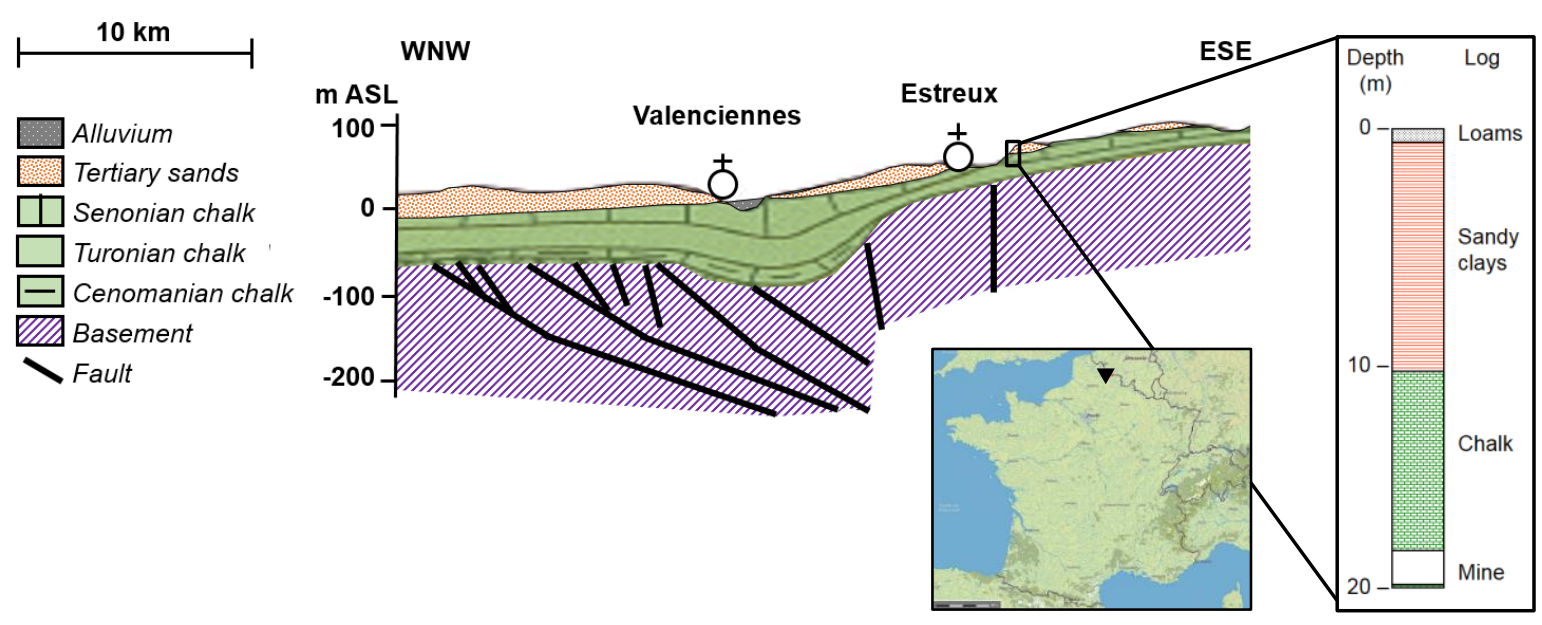

Figure 2. Geological map of the Estreux sector (Source: Infoterre) and piezometer log (Ineris) 


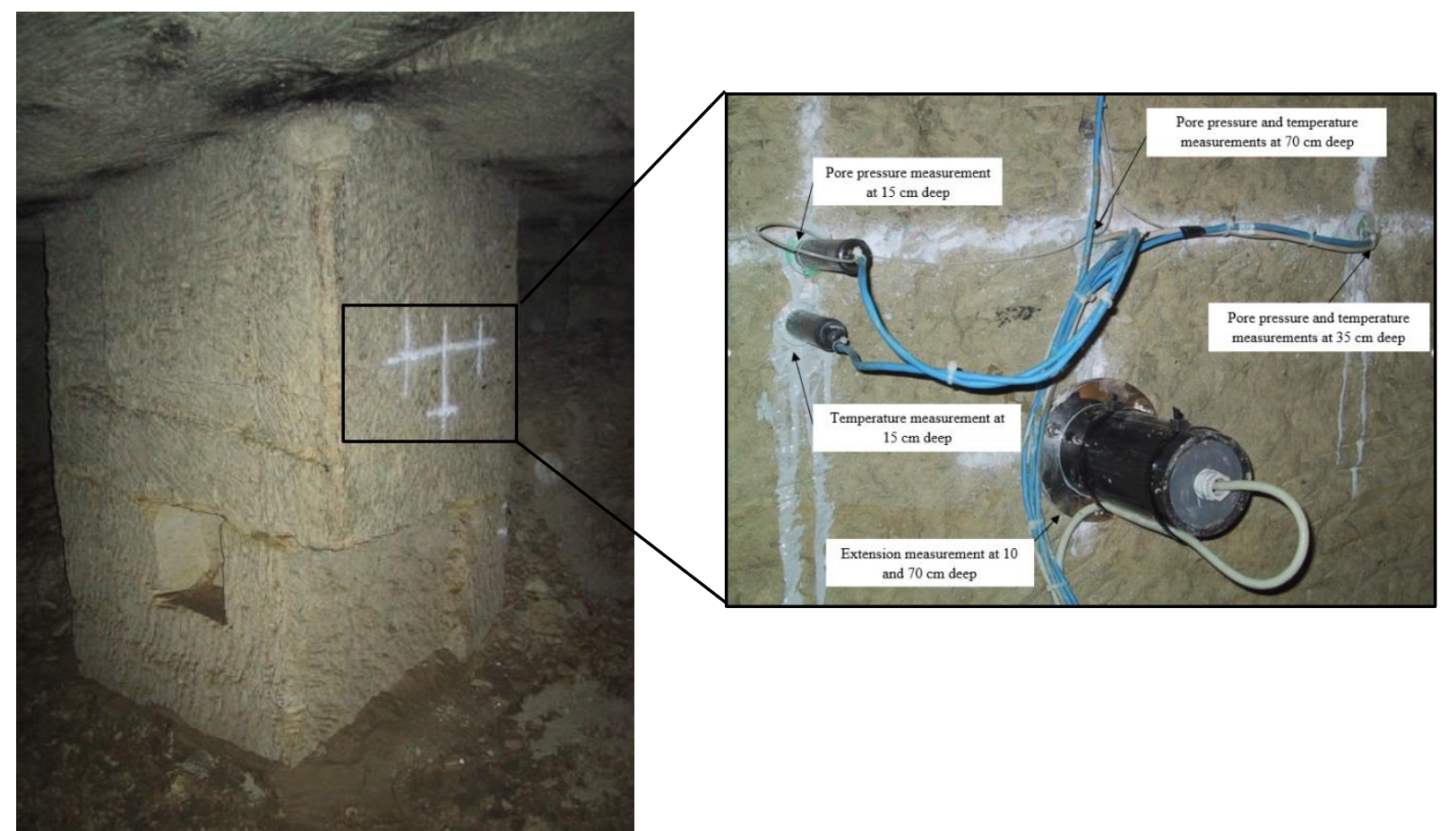

Figure 3. Initial view of the pillar (left) and detail of its instrumentation (right) 


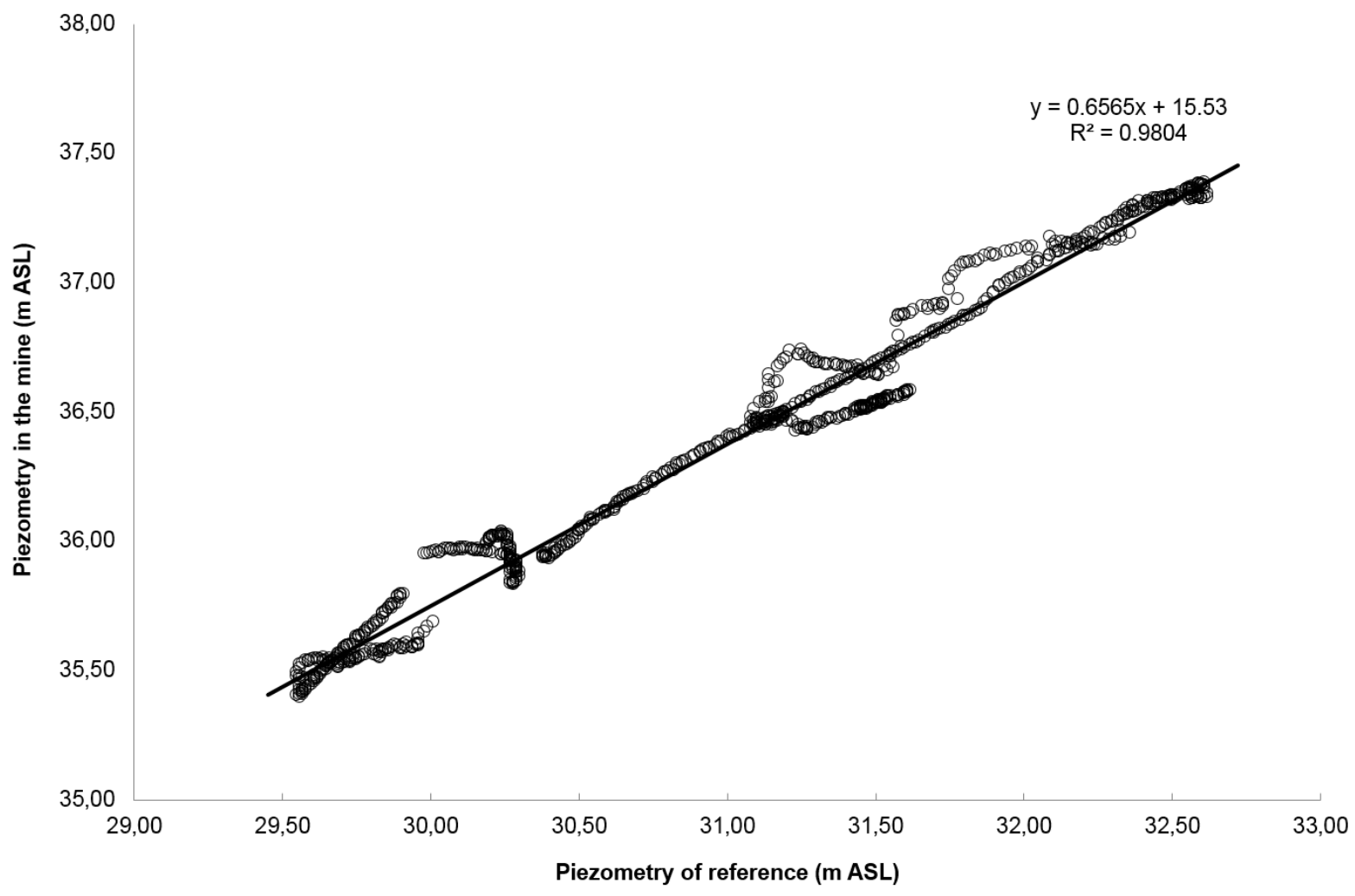

a) Plot of the mine piezometry versus the reference piezometry from 2007 to 2011 ( $R$ is the coefficient of determination)

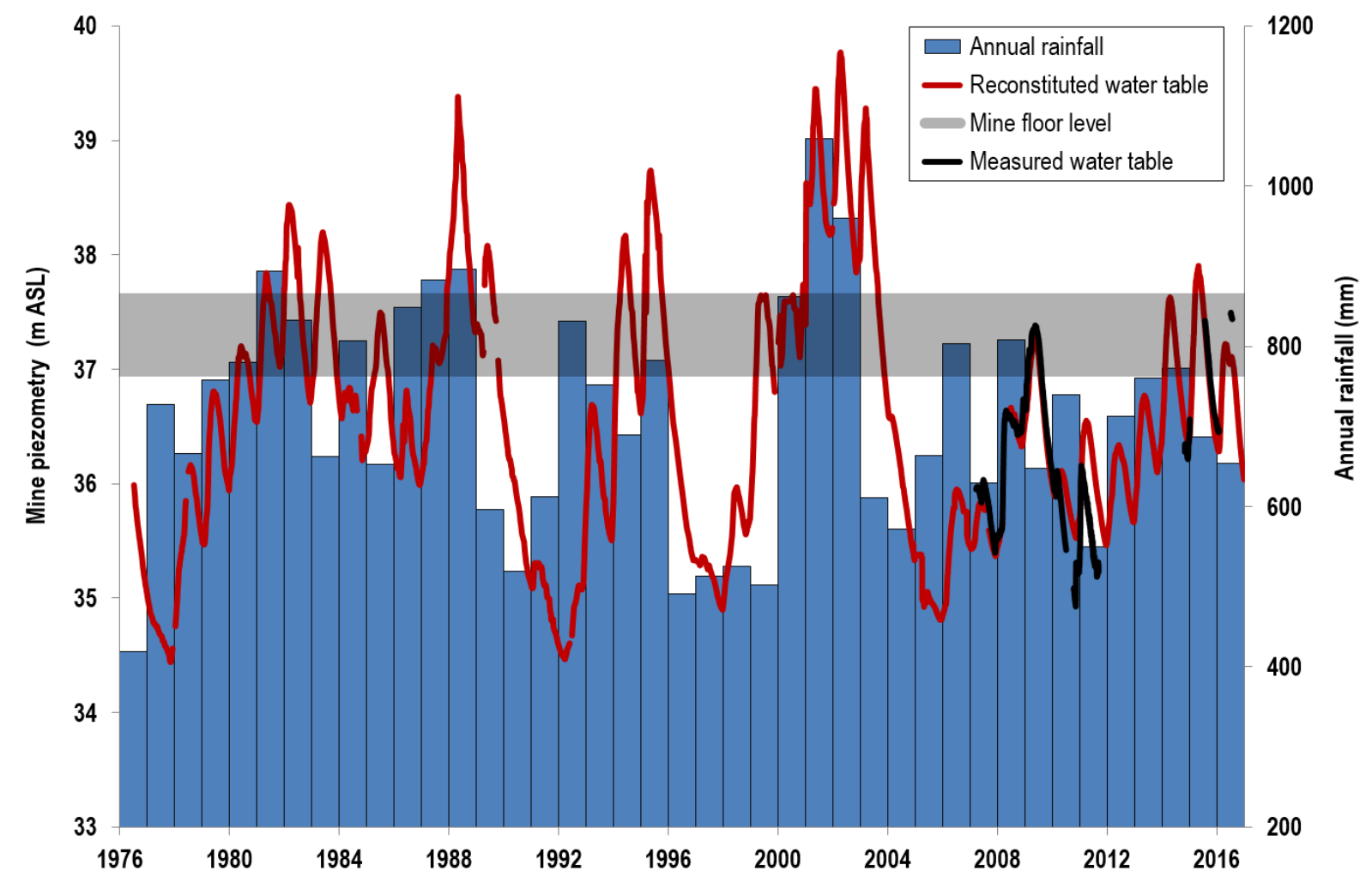

b) Daily reconstituted values of piezometry at the Estreux mine compared to measured values

Figure 4. Reconstituted piezometry at the Estreux mine from 1976 to 2016 


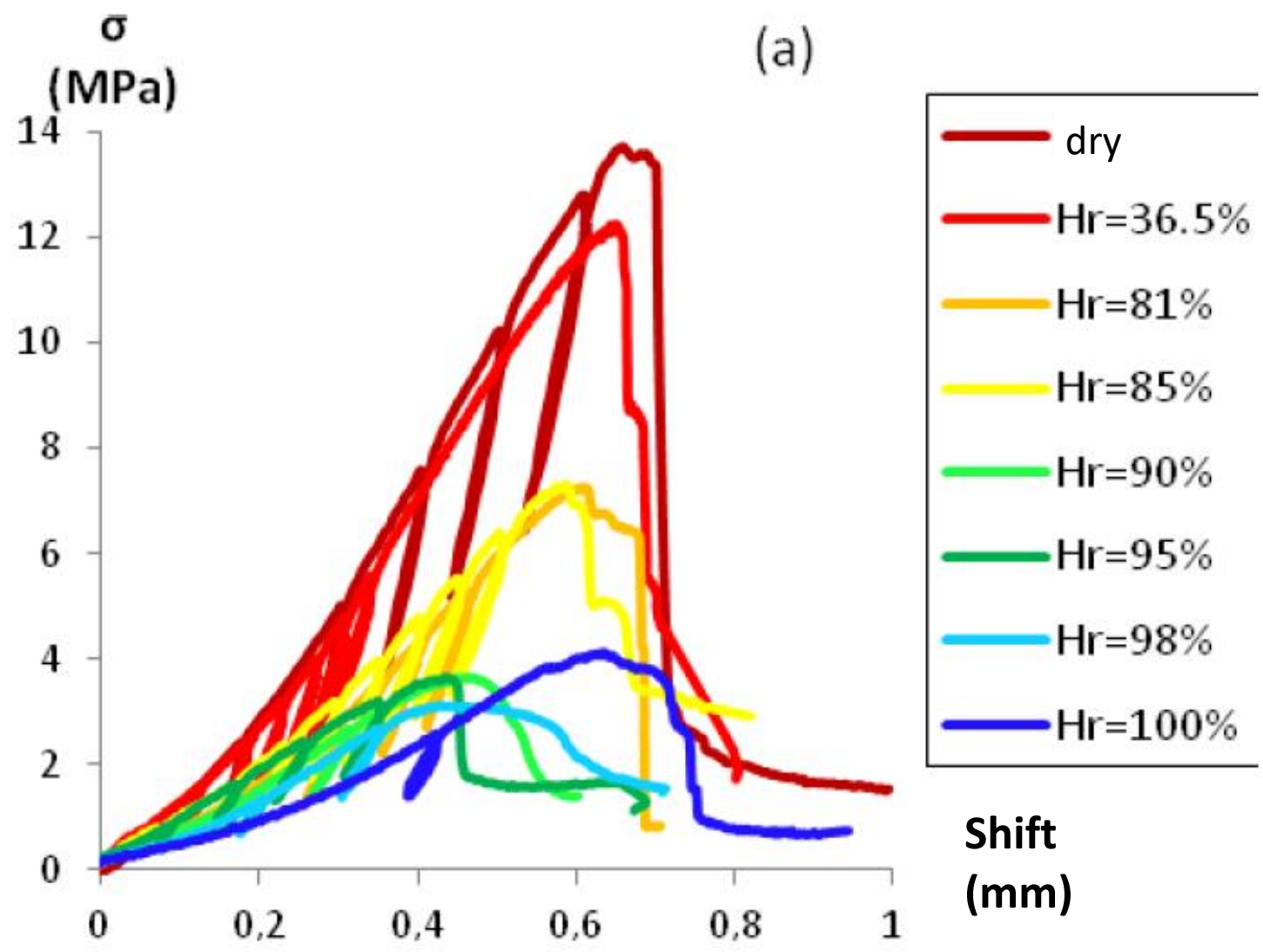

Figure 5. Impact of relative humidity $(\mathrm{Hr})$ on the relationship constraint $(\sigma)$-shifting (Shift) obtained with uniaxial compression tests for Estreux chalk (Lafrance et al. 2014) 


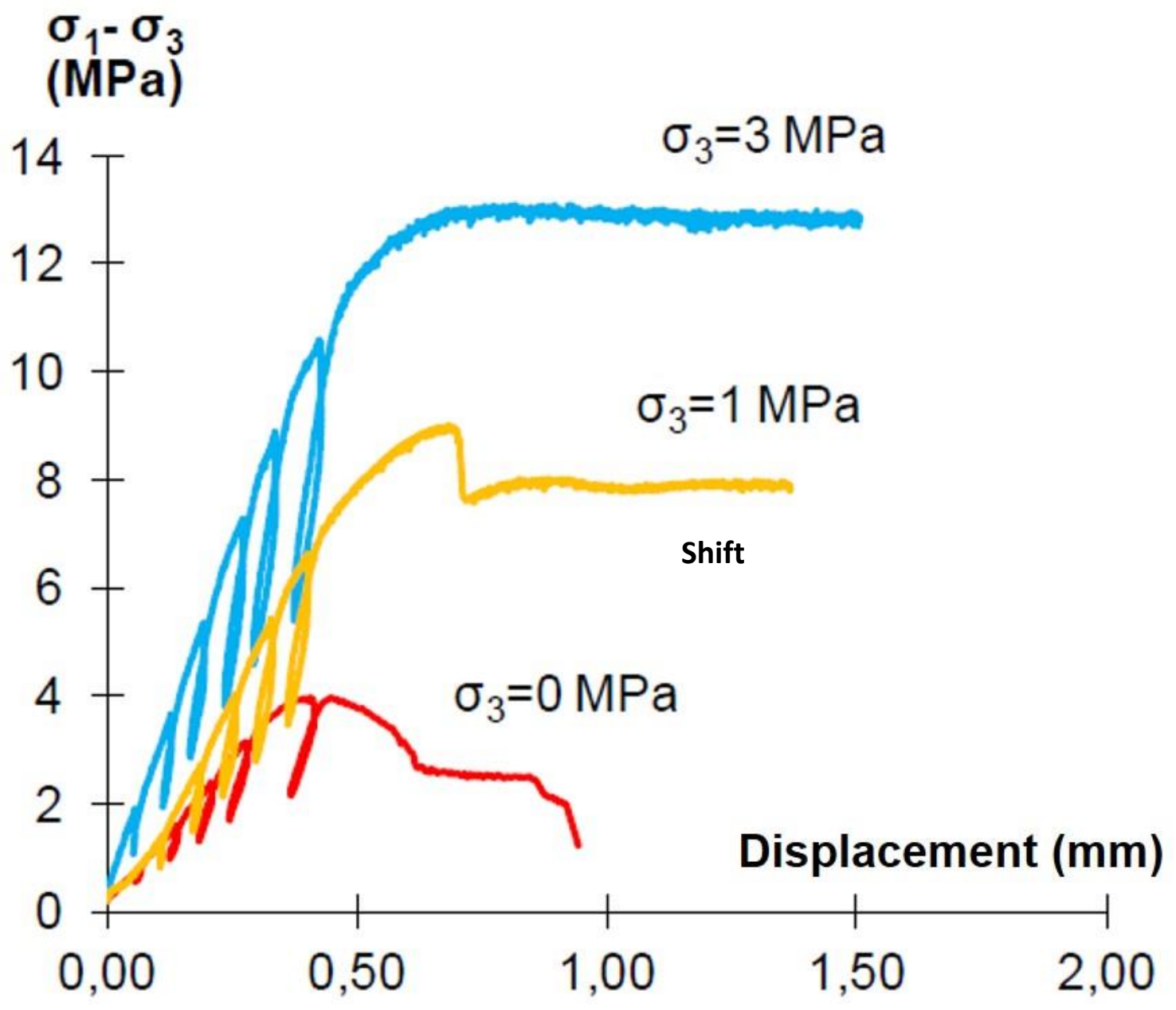

Figure 6. Triaxial tests at 0,1 and $3 \mathrm{MPa}$ of confinement for Estreux chalk at a saturated degree of $98 \%$ (Lafrance et al. 2014) 


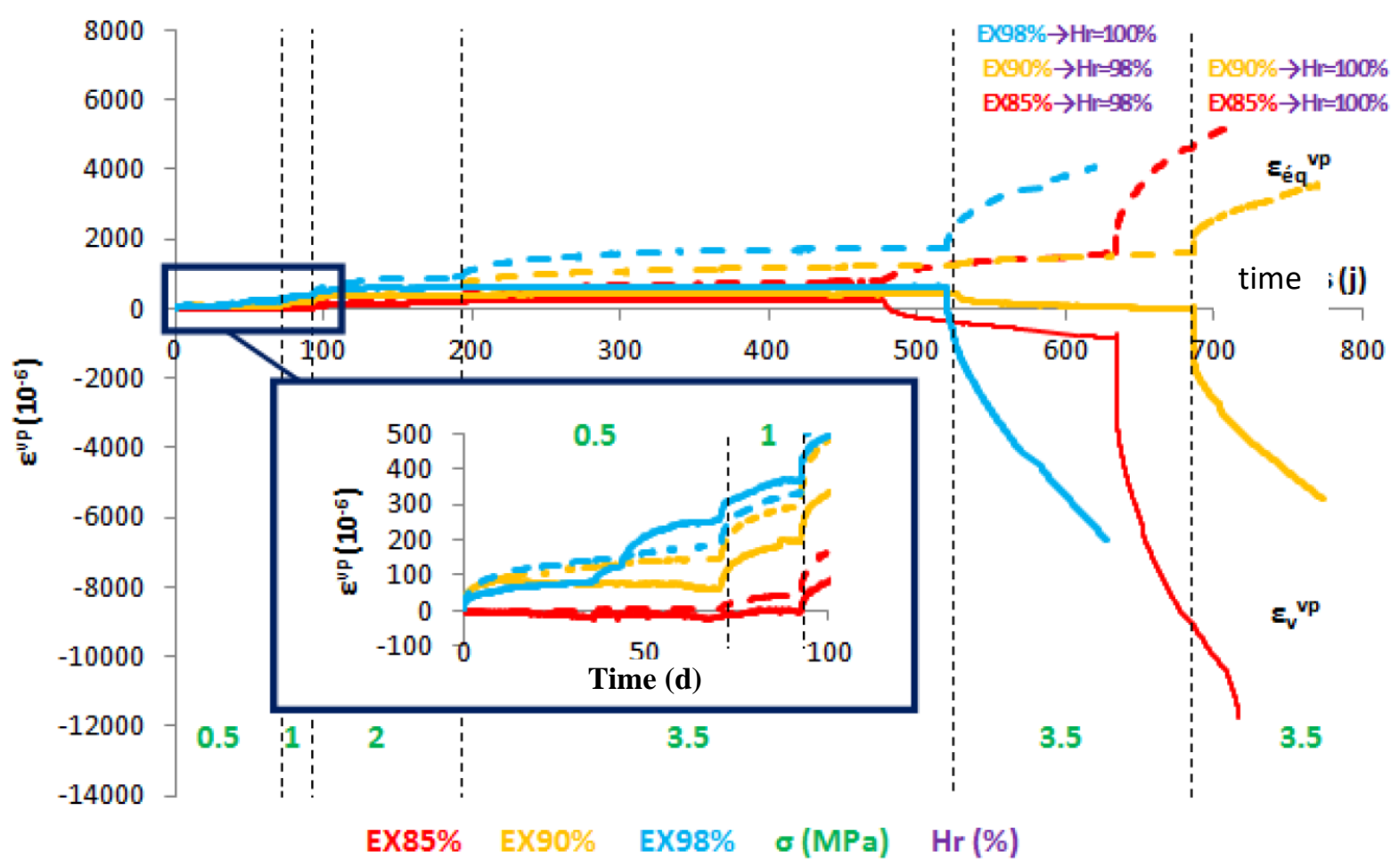

Figure 7. Creep curves of the partially saturated chalk samples of the Estreux chalk. Deformations deferred volumetrically and deviatorically as a function of time 


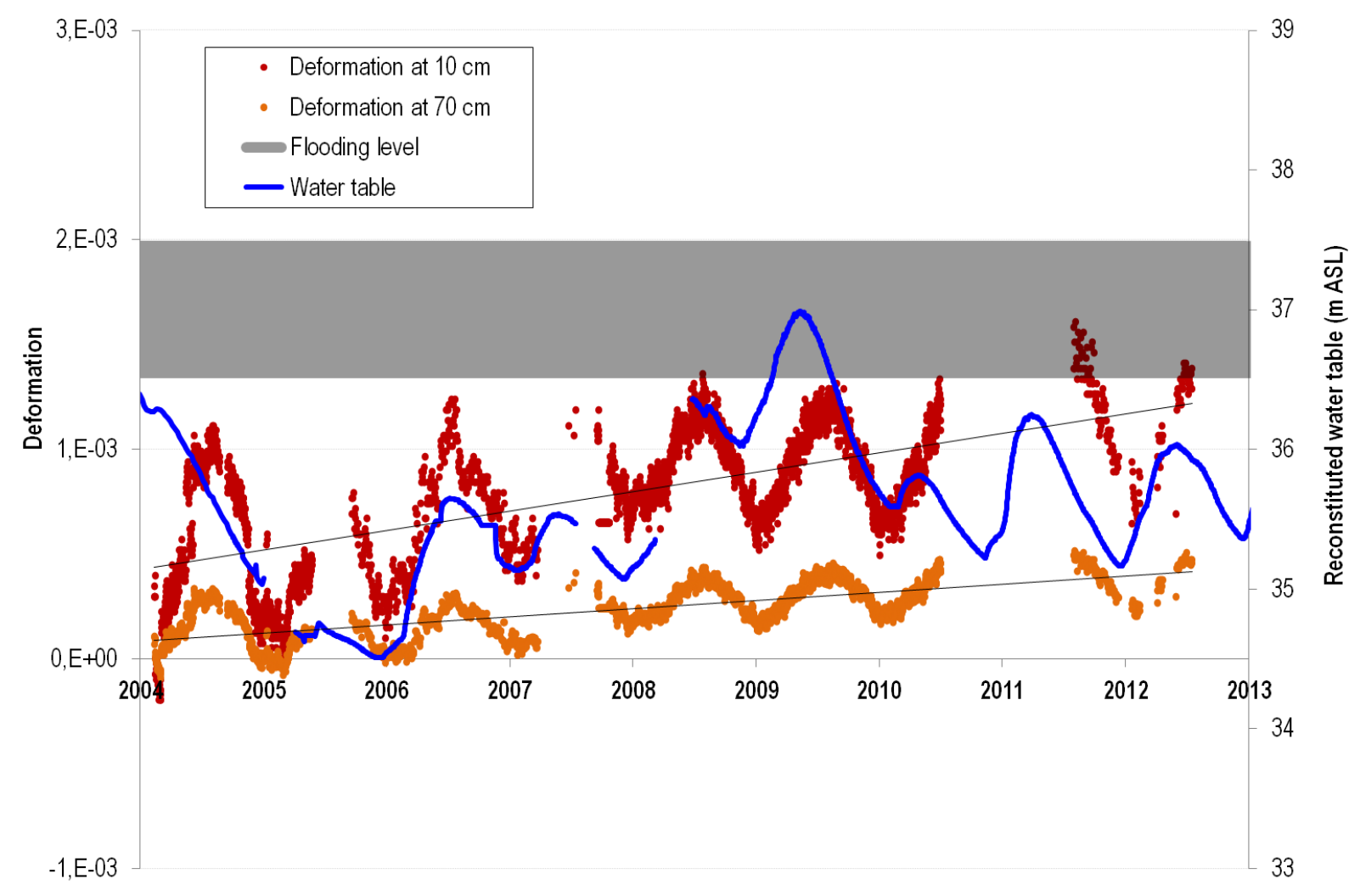

Figure 8. Evolution over time of the horizontal deformation of the pillar 


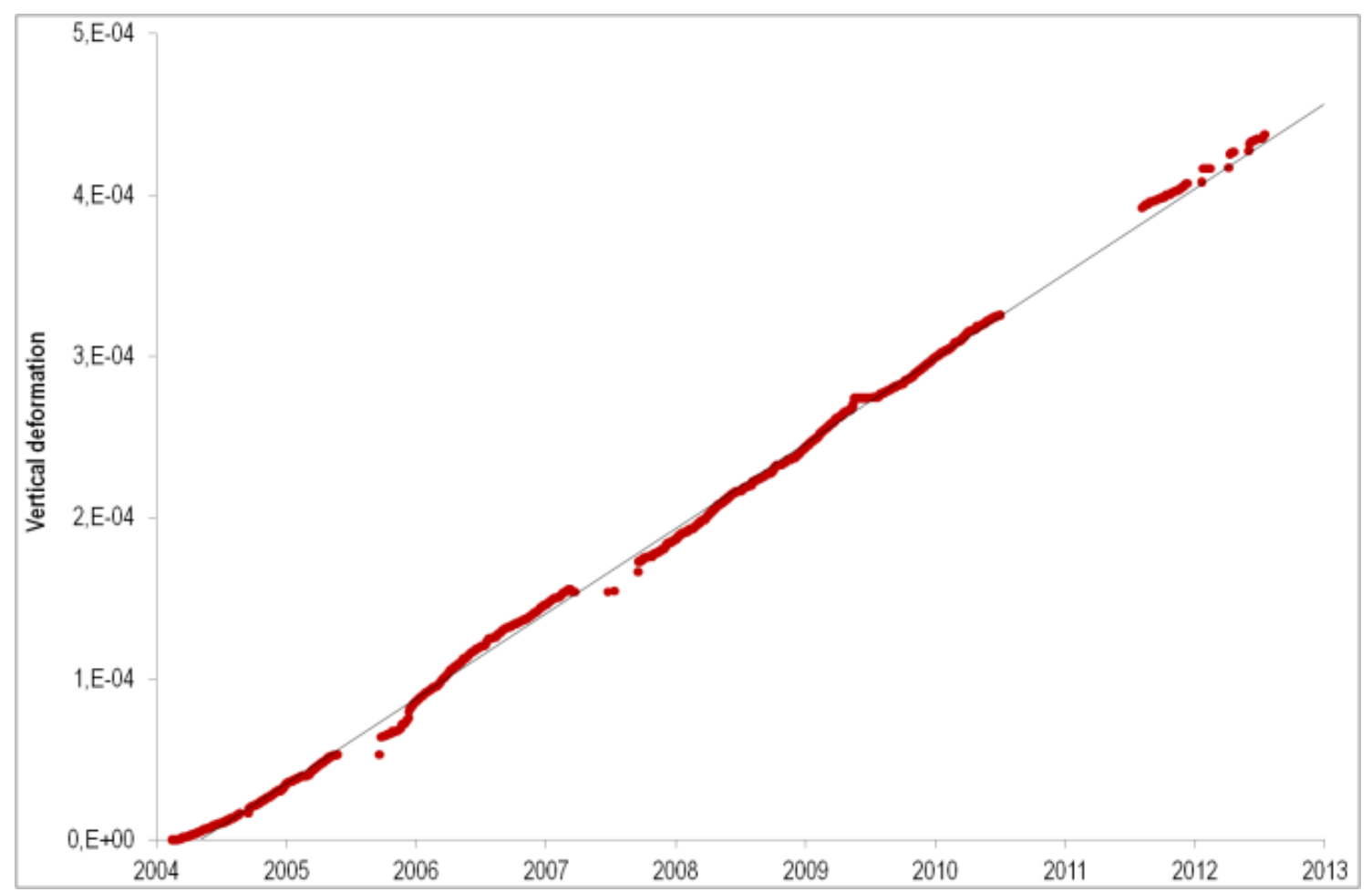

a) Roof-floor measures of convergence

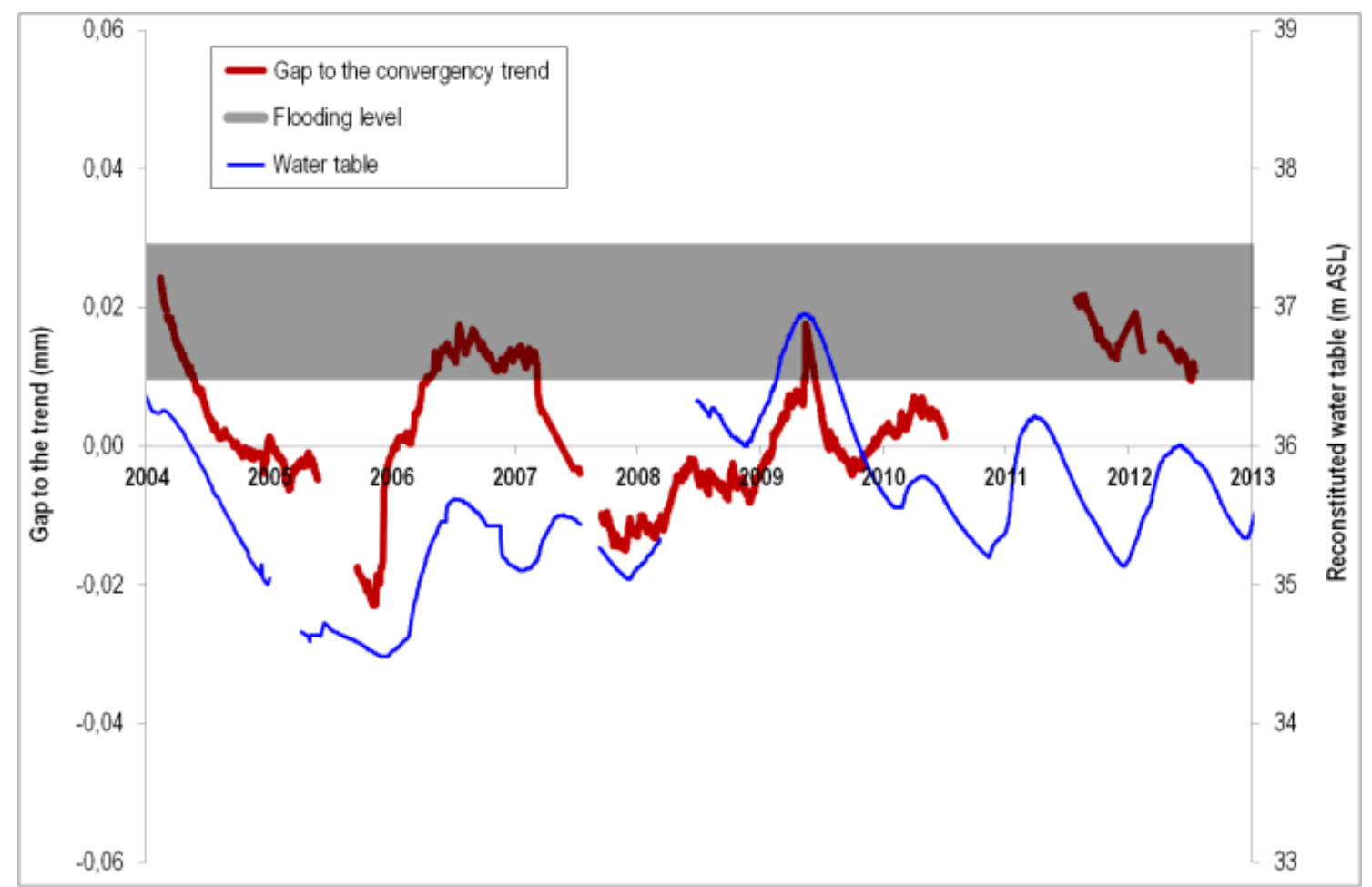

b) Deviation at the mean line

Figure 9. Evolution over time of the vertical deformation of the pillar 


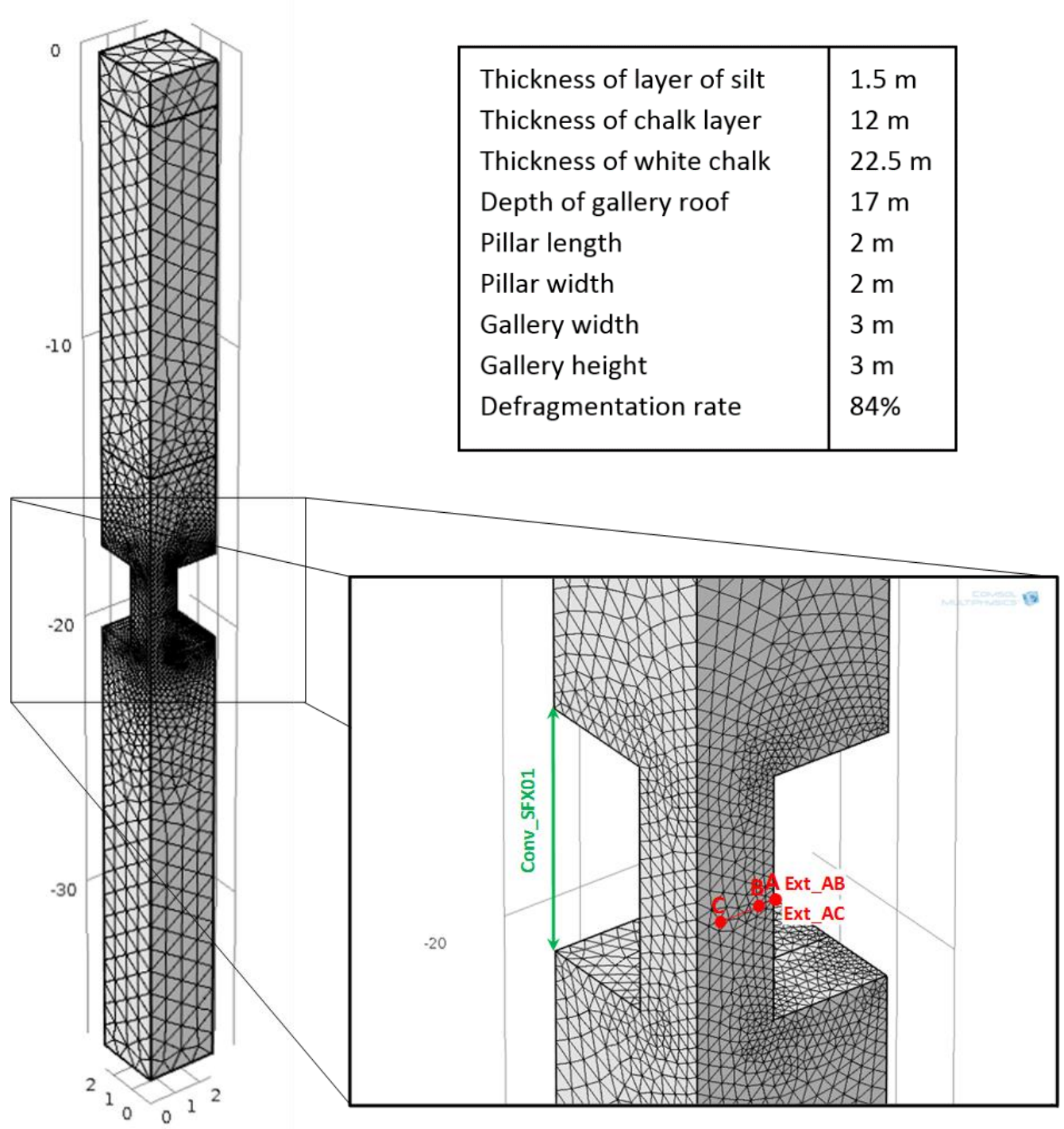

Figure 10. Geometry and mesh of the 3D model pillar realized (all units in meters) 


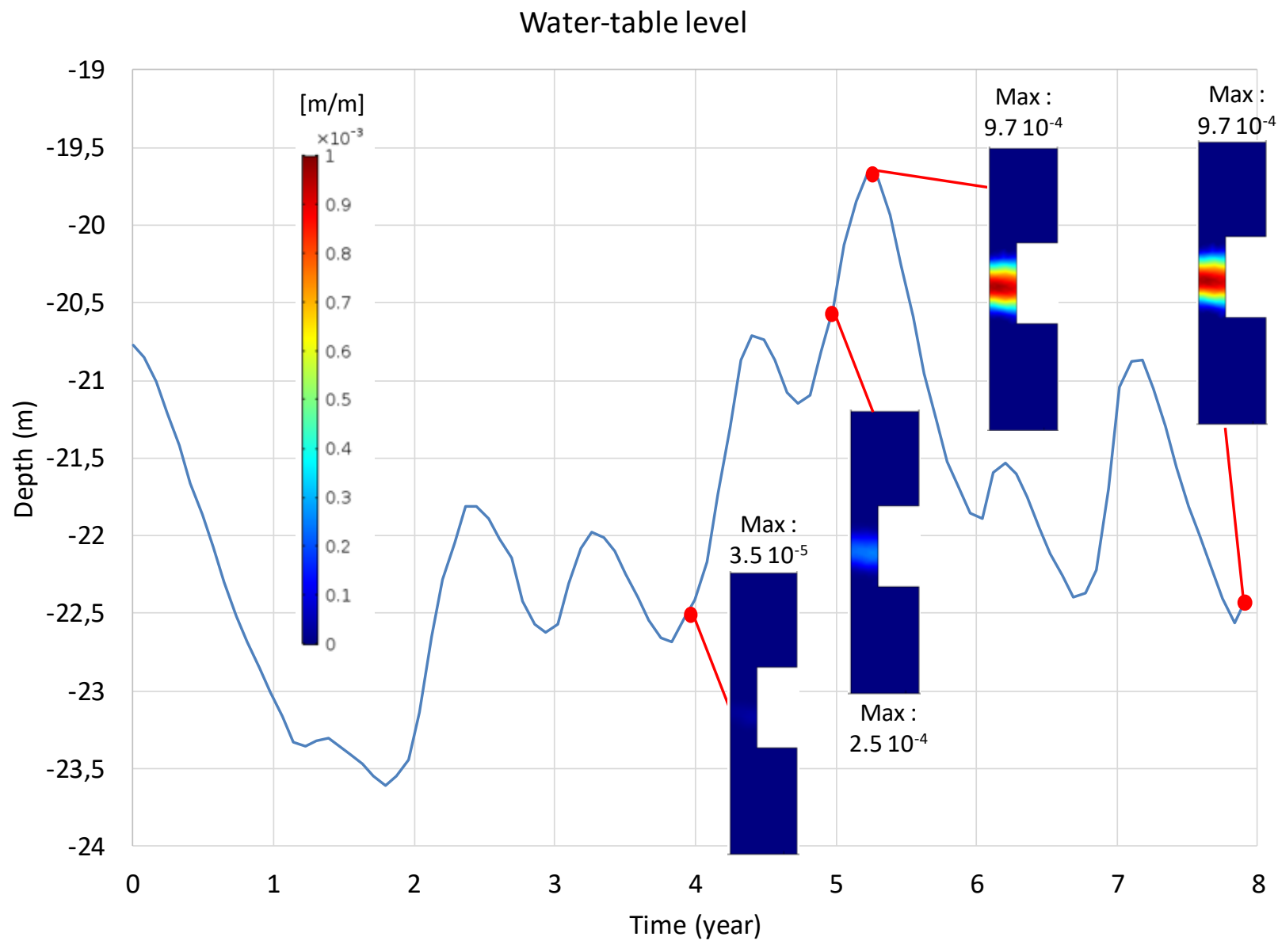

Figure 11. Evolution of the effective plastic strain over time $\left(\mathrm{t}_{0}=01 / 01 / 2004\right)$ taking into account the fluctuation of the water table $\left(\mathrm{C}_{2}=0.6 * \mathrm{C}_{\mathrm{lab}}\right)$. Colored scale refers to deformation. 


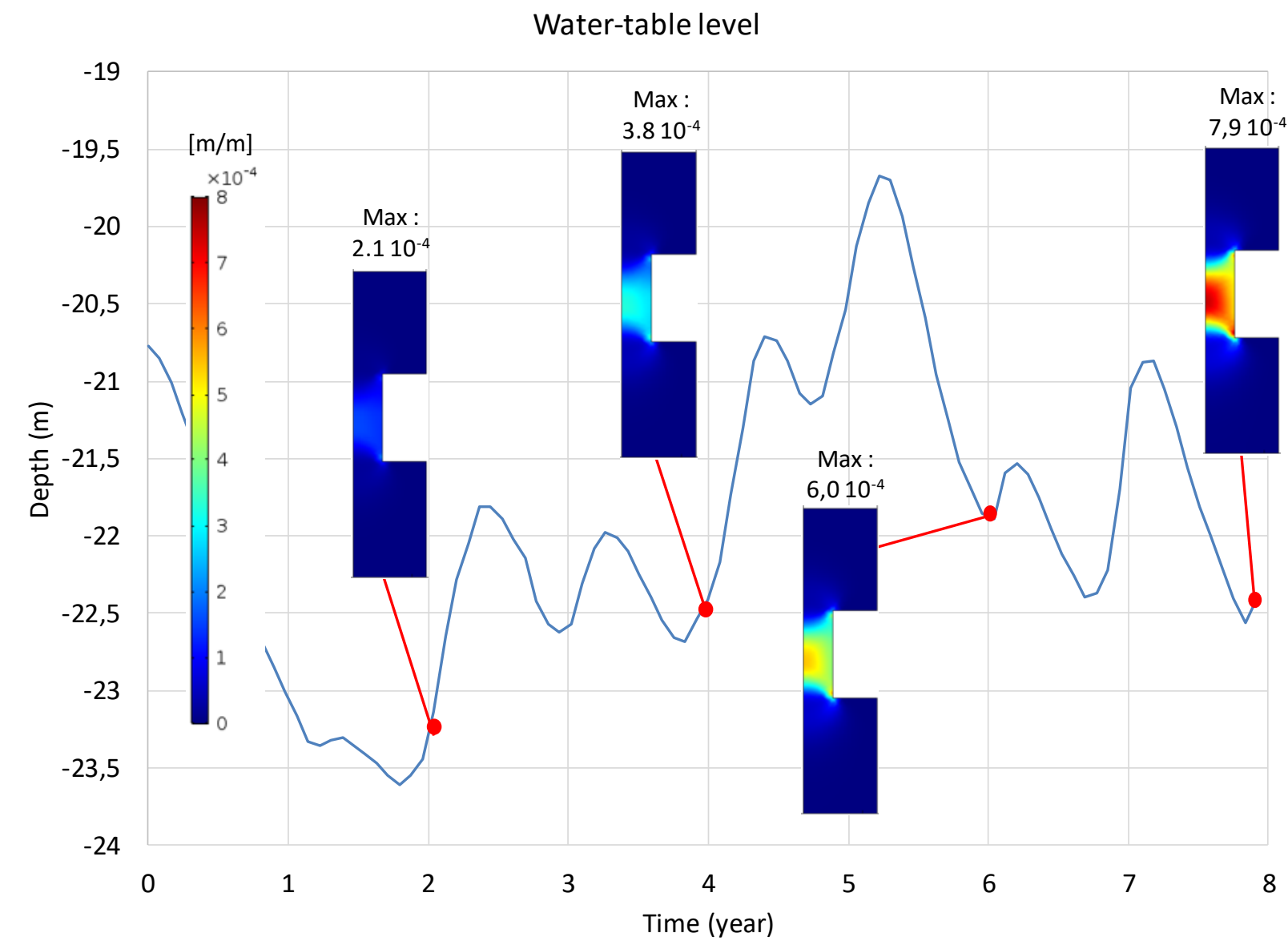

Figure 12. Evolution of the effective creep strain over time $\left(\mathrm{t}_{0}=01 / 01 / 2004\right)$ taking into account the fluctuation of the water table $\left(\mathrm{C}_{2}=0.6 * \mathrm{C}_{\mathrm{lab}}\right)$. Colored scale refers to deformation. 


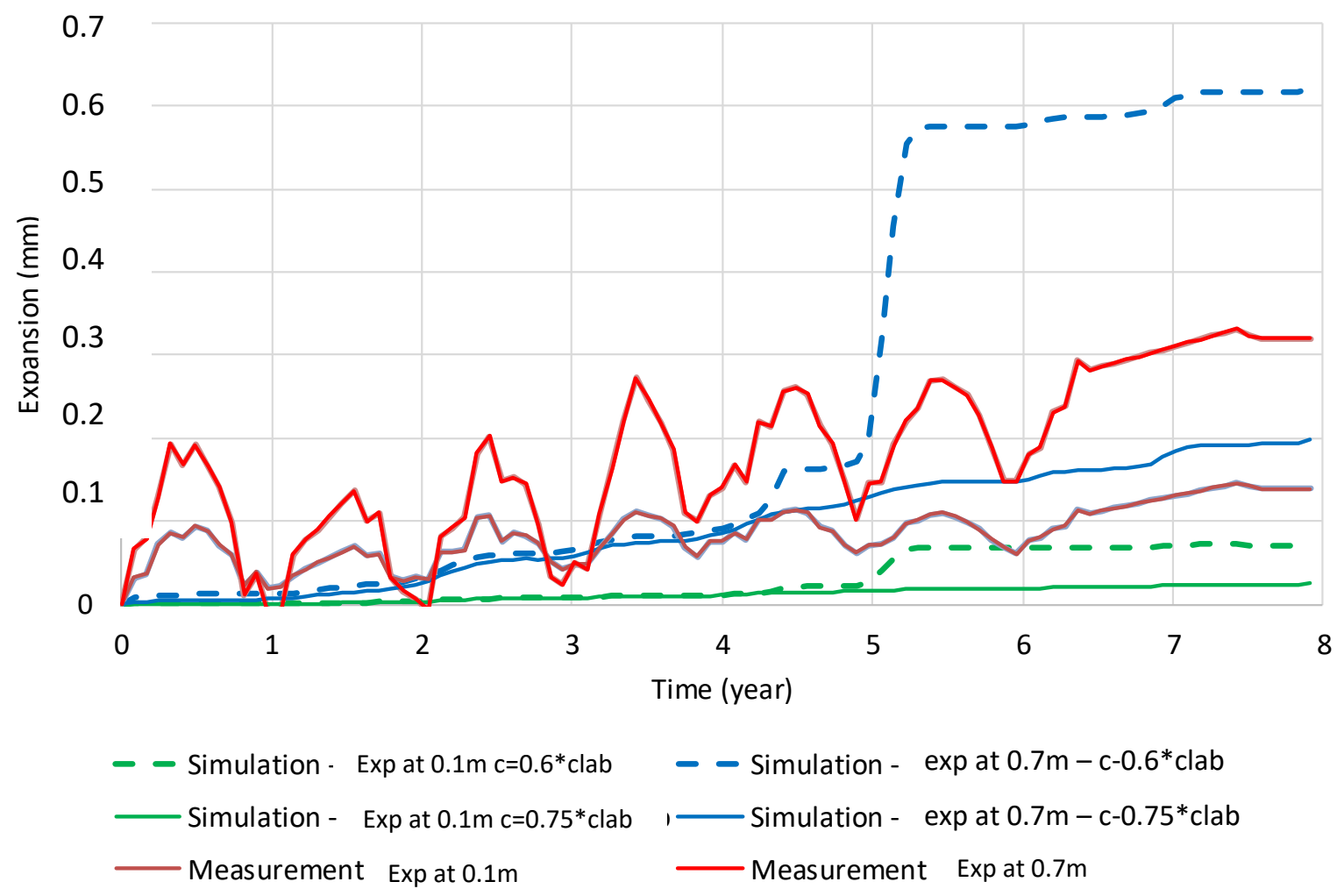

Figure 13. Comparison of the horizontal extension modeled and measured in the pillar 


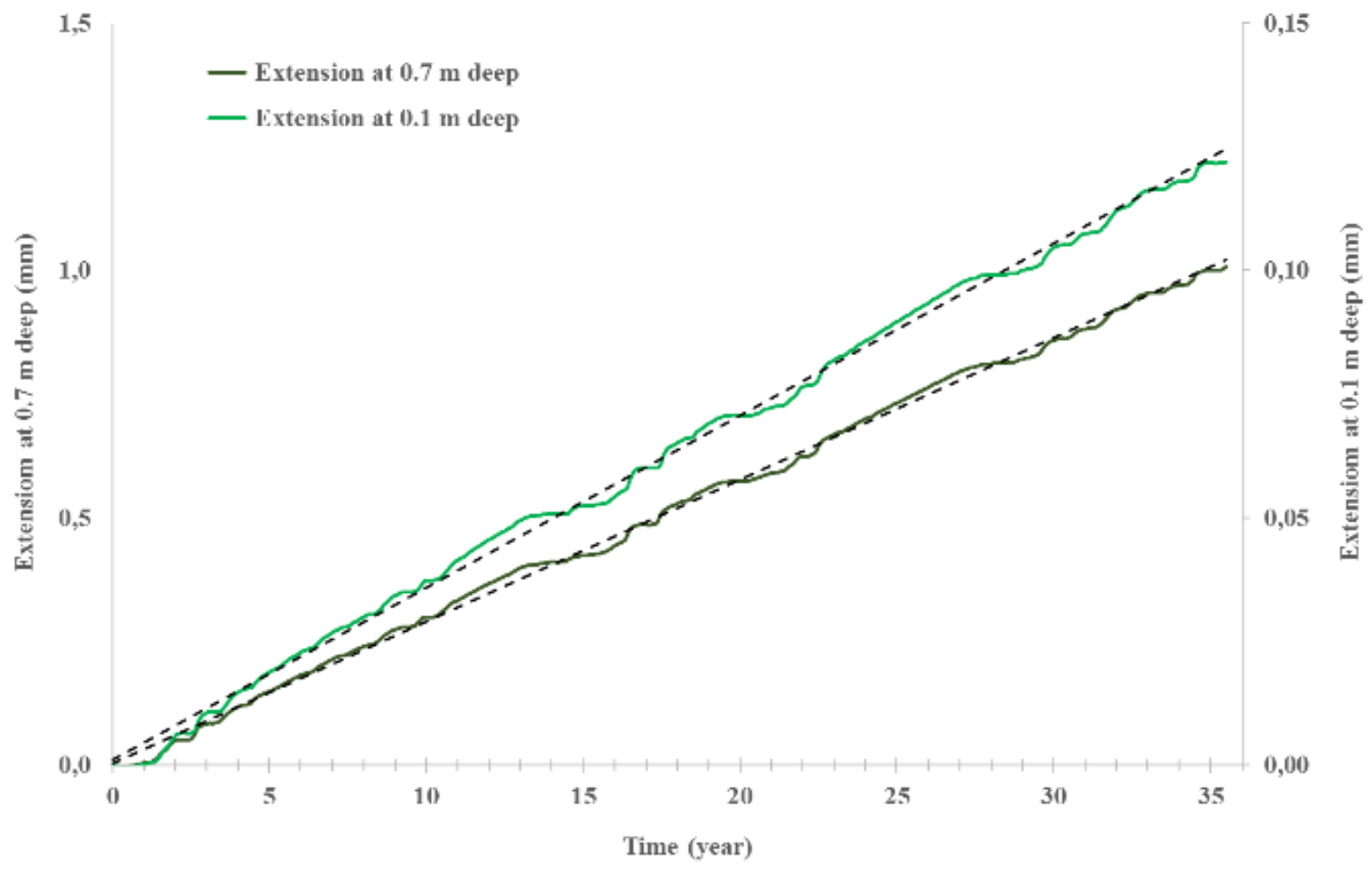

a) Evolution of convergence and trend

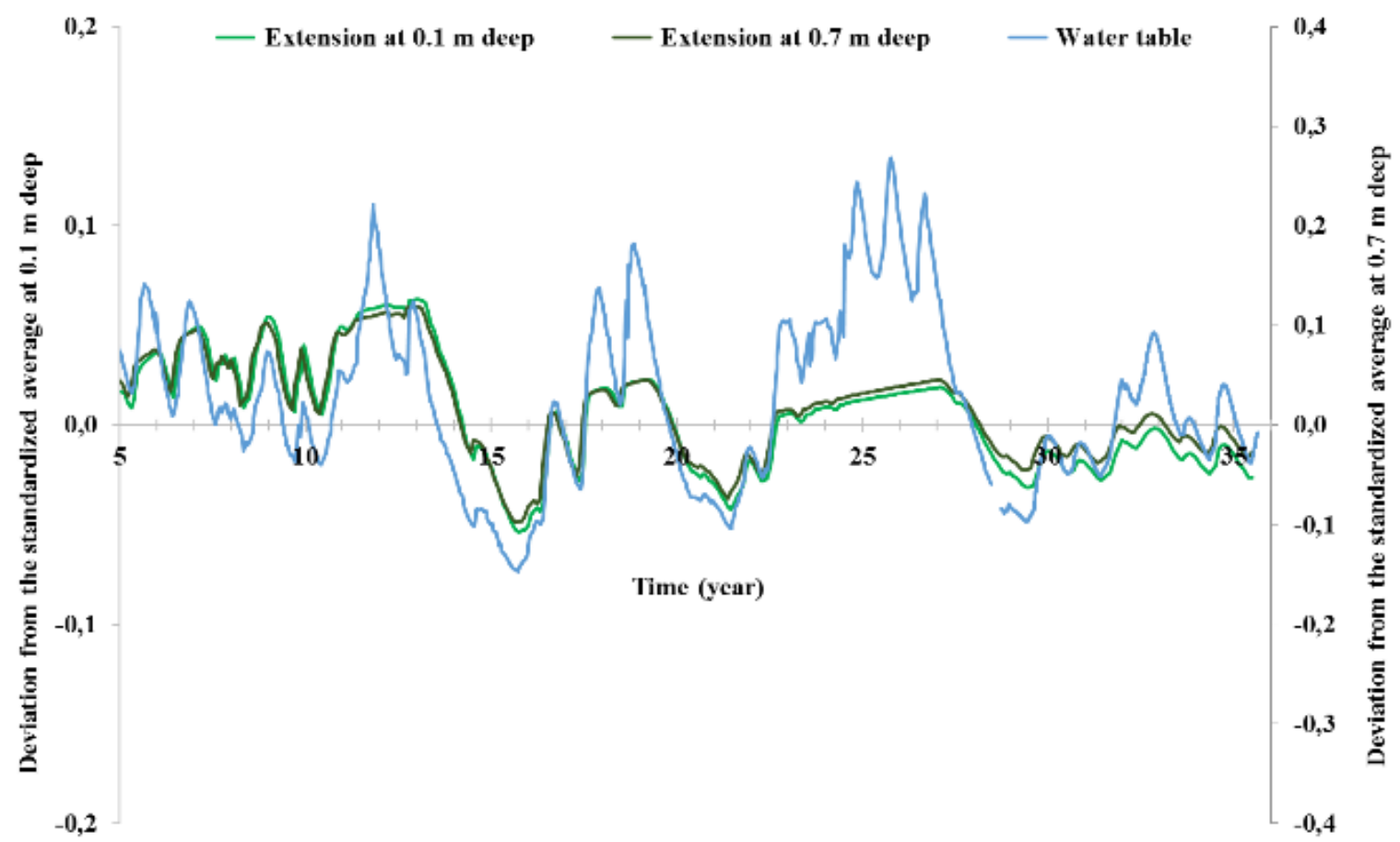

b) Oscillations of extension and water table

Figure 14. Evolution of the extension (a) and comparison of its oscillations with those of the water table (b) 


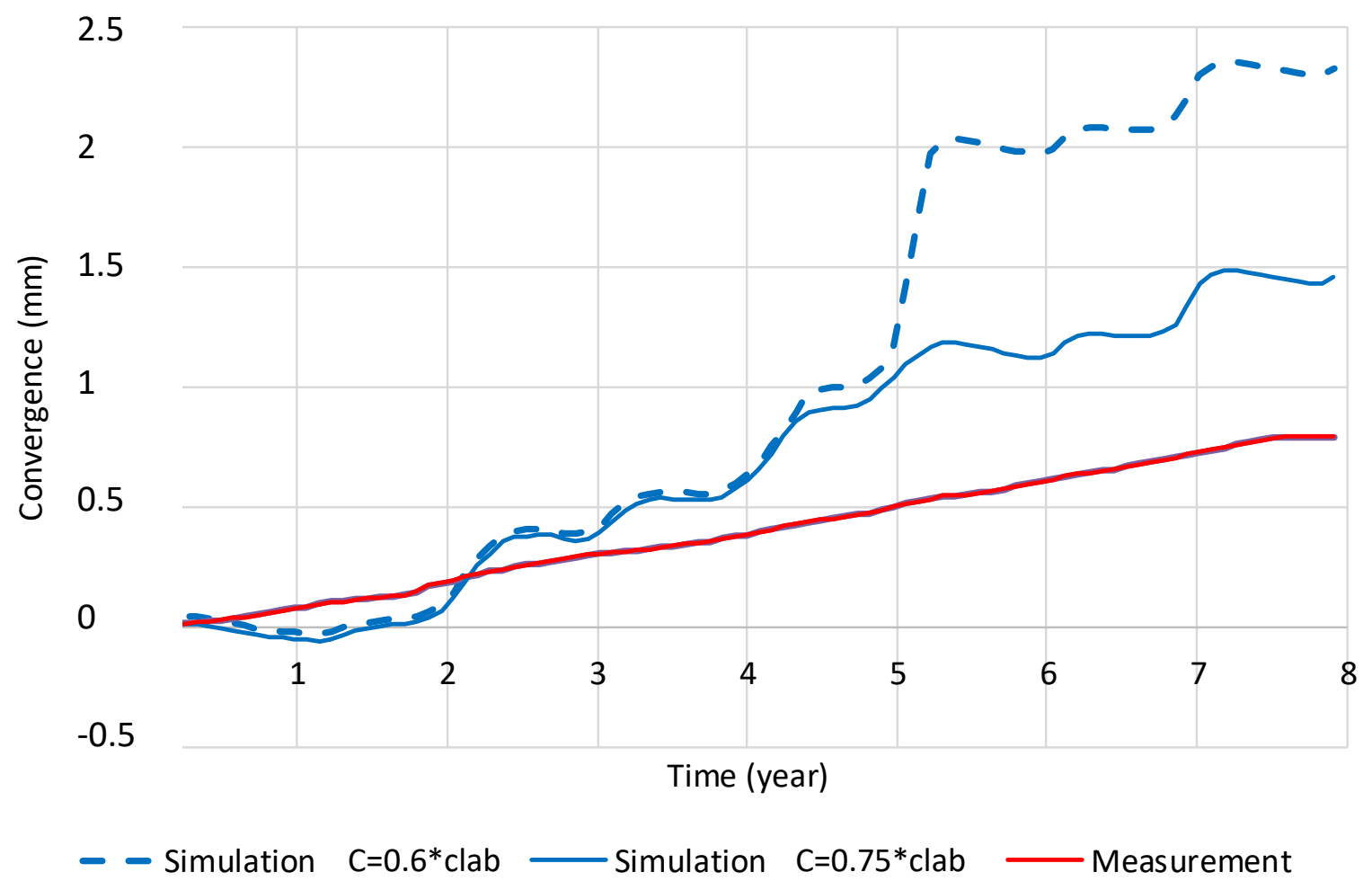

Figure 15. Comparison of measured and calculated vertical convergences for the Estreux mine 


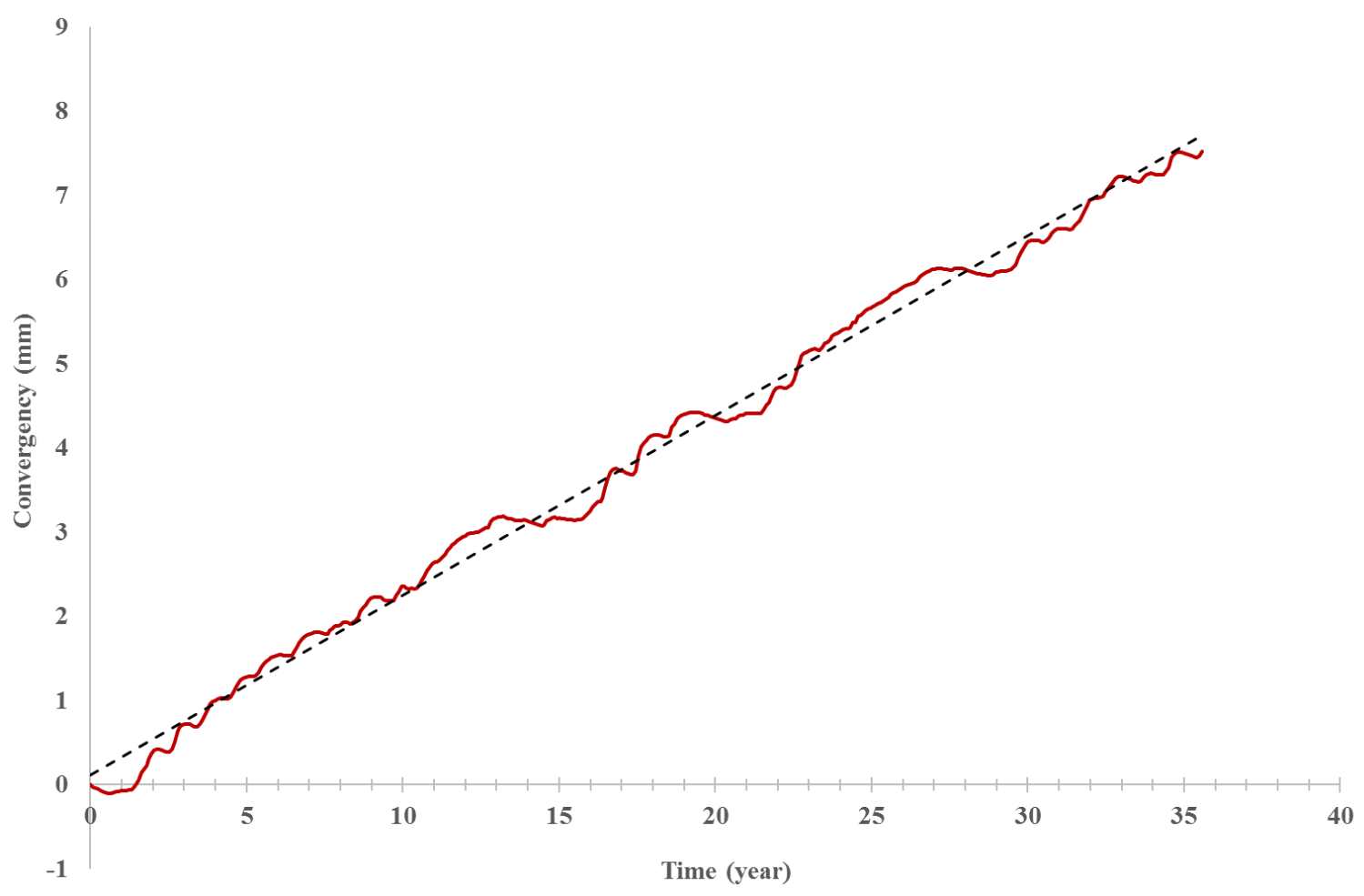

a) Evolution of convergence and trend

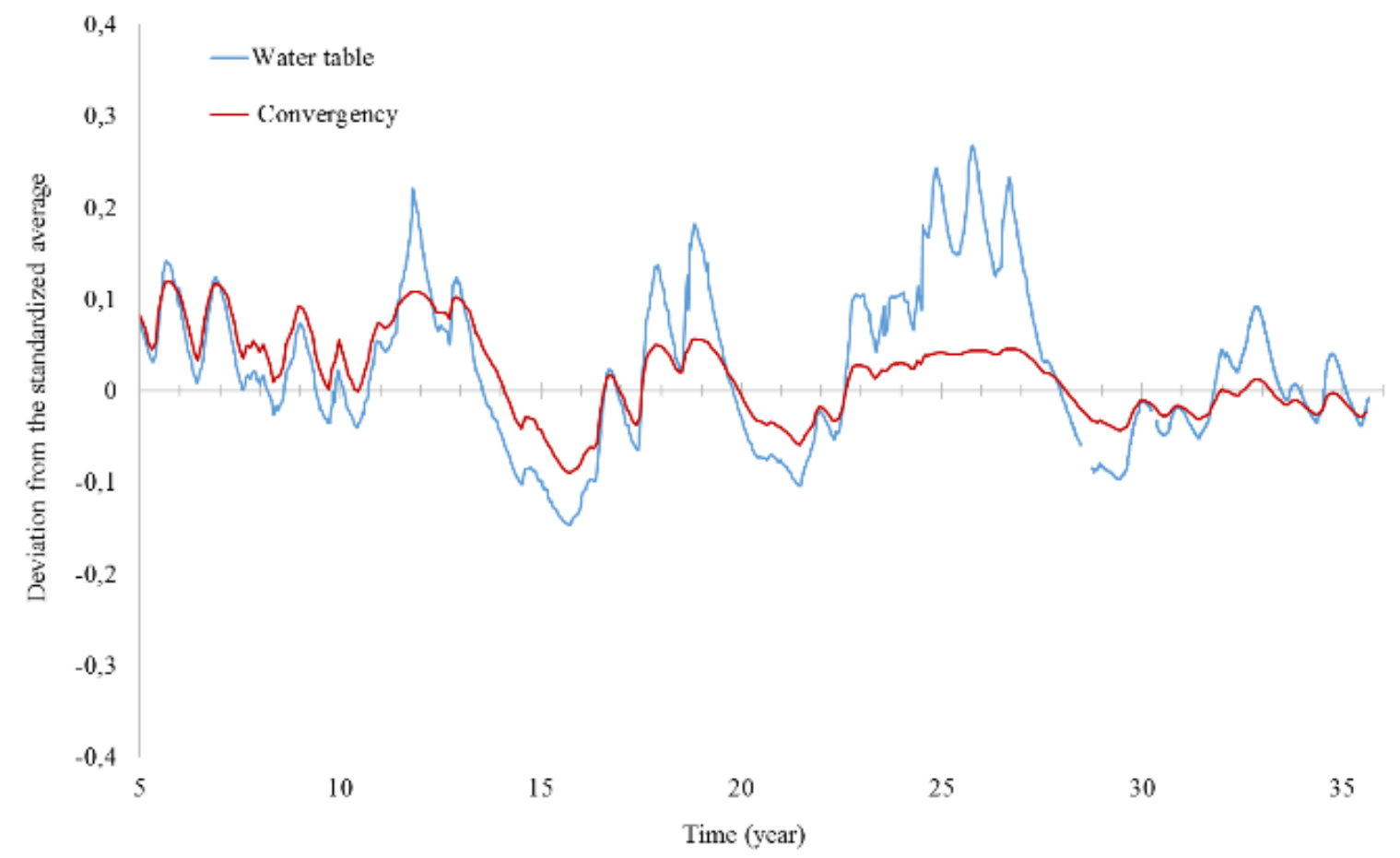

b) Convergence and water table oscillations

Figure 16. Evolution of the convergence (a) and comparison of its oscillations with those of the water table (b) 